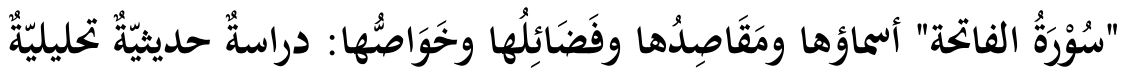

\section{The Chapter of Fatiha; Its Names, Objectives, Virtues and Features: Analytical Study of the Relevant Hadith Literature}

Dr. Syed Abdul Majid Ghouri*

\begin{abstract}
The Chapter of Fatiha is conceived as one of the paramount chapters of the Holy Qur'an; rather, it is unprecedented one in the sense that not a similar chapter has been revealed in any of revealed Books including the Qur'an itself. Also, as many prophetic traditions have been narrated with regard to its virtues as not narrated concerning any other chapter; the objectives of this chapter have extensively been discussed more than other chapter; and this chapter is characterized by having many names more than all other chapters. Moreover, this chapter, despite of being conciseness, comprises of three types of Tawhid (Oneness of God); namely, Oneness in terms of Lordship, Oneness in terms of Divinity, and Oneness in terms of Names and Attributes. Similarly, this chapter is characterized with many other features: such as the role of this chapter in attracting benefits and removing harms, healing of deceased, (getting divine) guidance, and fulfilling necessities. In addition to this, the Qur'an begins with this chapter. It is stated that it is one of the basic elements of the prayer without which prayer does not stand valid. It, by all means, indicates to the sublime nature, great features and magnificent virtues that this chapter holds. This work analyses the prophetic traditions narrated concerning this chapter and focuses over its objectives, names, virtues and characteristics in the light of authentic prophetic traditions. Meanwhile, the researcher adopts hybrid methodology: namely inductive one and critical one. On the one hand, critical method is adopted for searching and gathering all relevant traditions that discuss in one way or another this chapter; and, on the other hand, inductive method is adopted for analyzing the relevant traditions and drawing significant conclusions therefrom. At the end, a conclusion is added that contains several important remarks which have been drawn while this study.
\end{abstract}

Keywords: The Chapter of Fatiha, Analytical Study, Hadith, Names, Objectives, Virtues.

$$
\begin{aligned}
& \text { الملحخَّص: }
\end{aligned}
$$

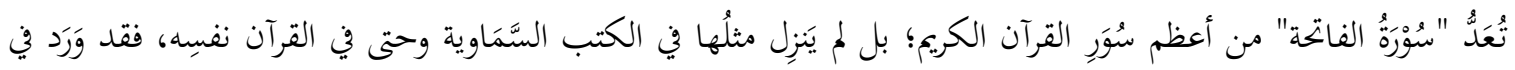

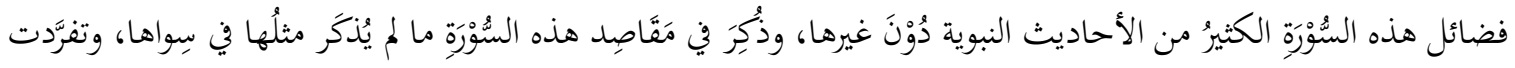

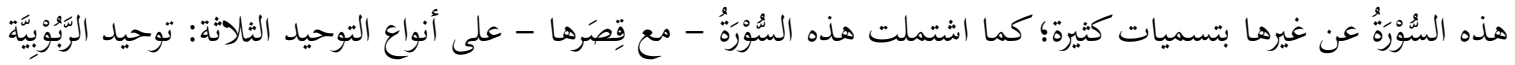

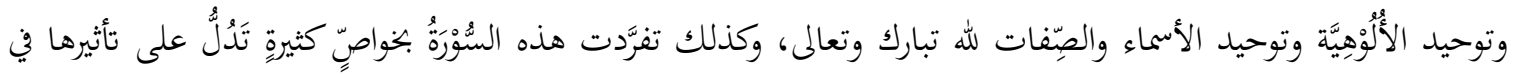

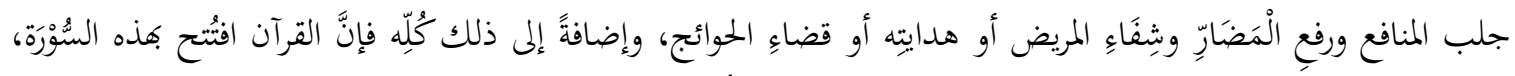

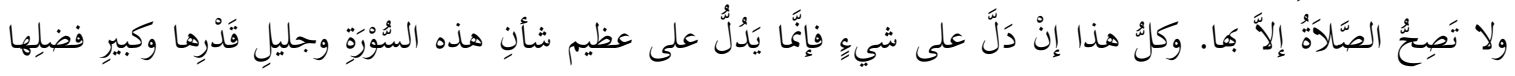

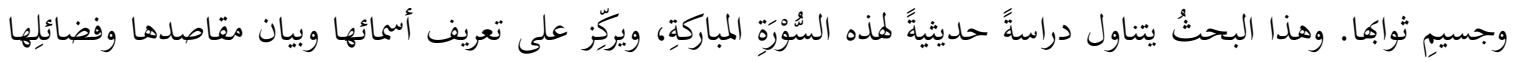

${ }^{*}$ Assistant Professor, Faculty of Quranic and Sunnah Studies, Islamic Science University of Malaysia (USIM), Malaysia. Email: samghouri@usim.edu.my 


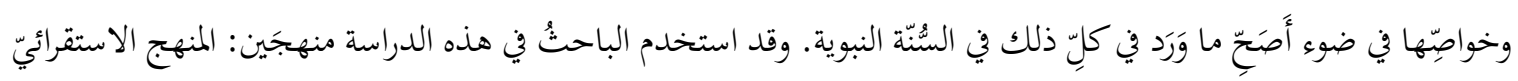

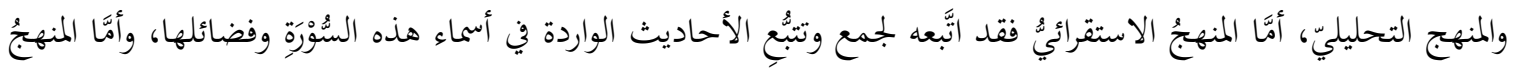

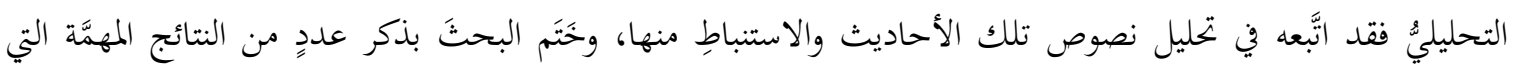
استخلصها من هذه الدراسة.

الكلمات الافتتاحية: سورة الفاتحة، دراسة حديثية تحليلية، أسماء، مَقَاصِد، فضائل، خَوَاصٌ.

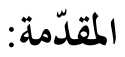

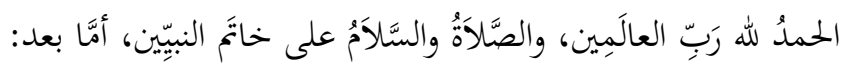

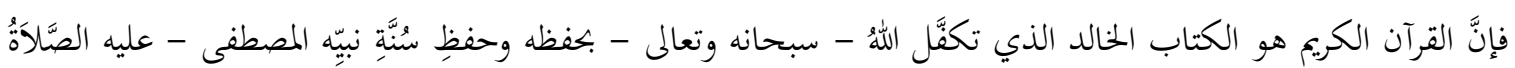

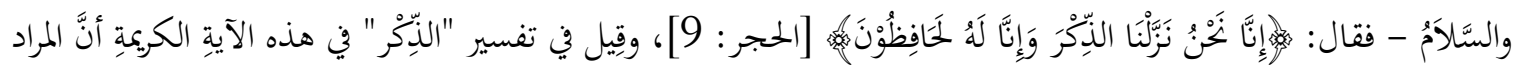

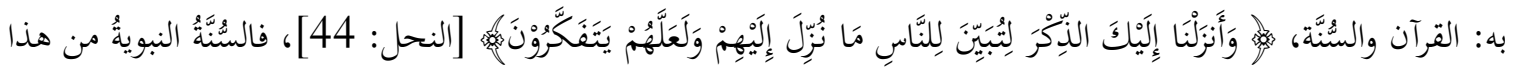

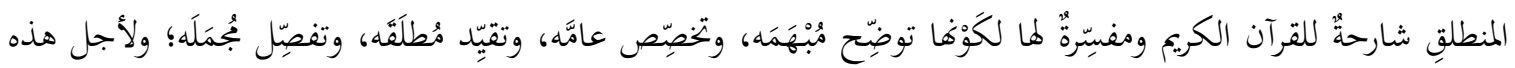

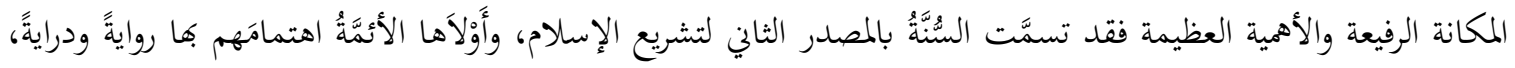

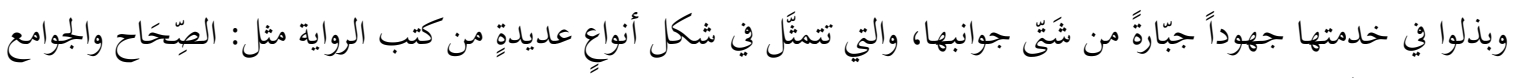

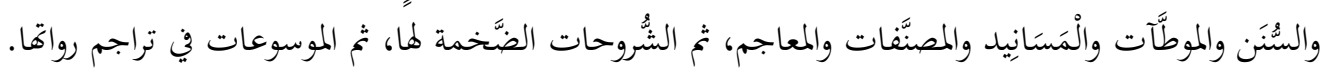

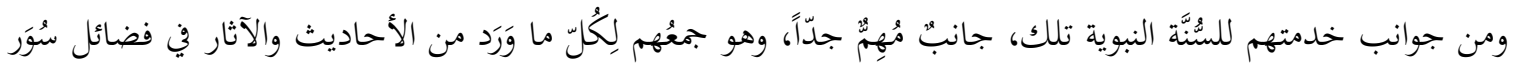

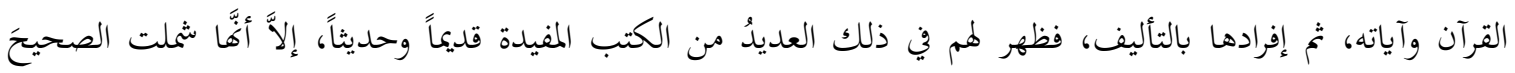

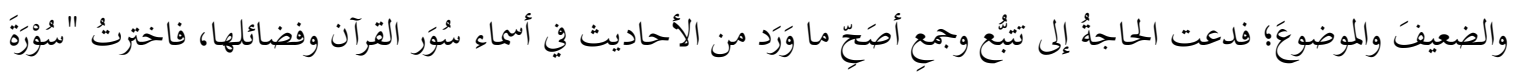

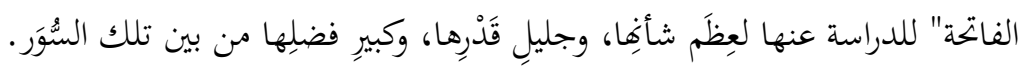

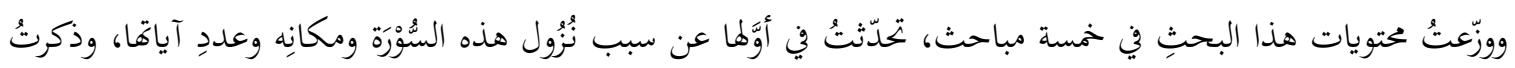

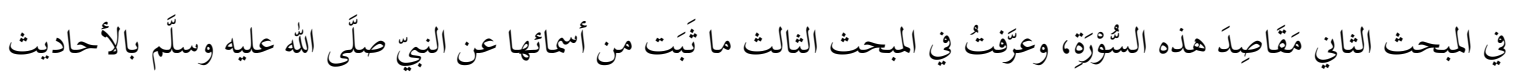

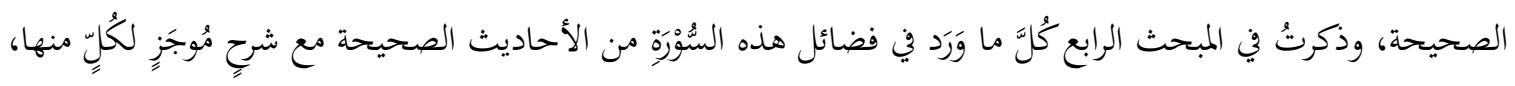

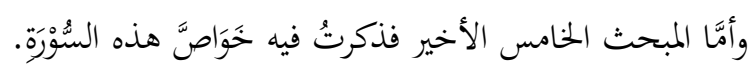

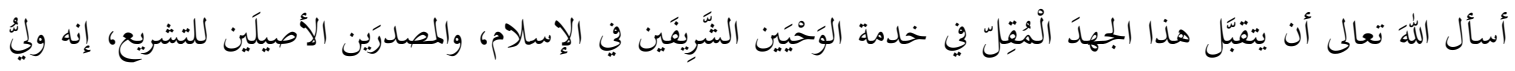
ذلك والقادر عليه.

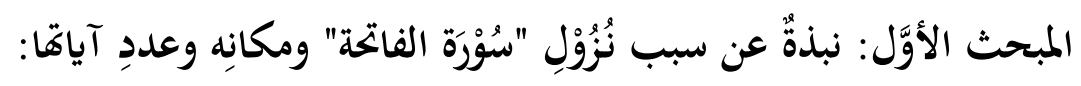

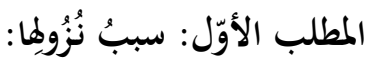

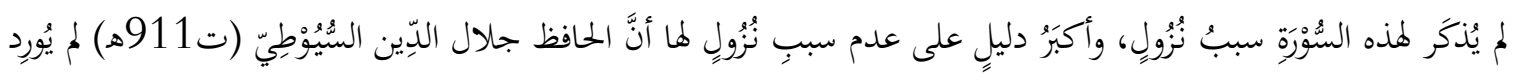




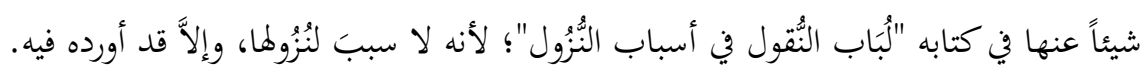

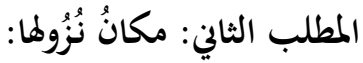

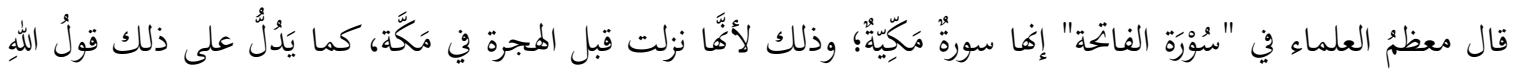

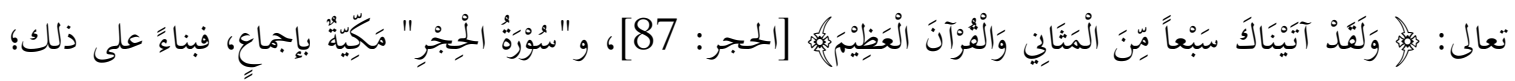

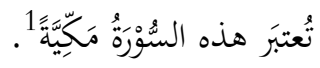

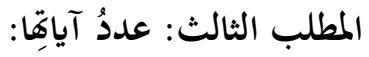

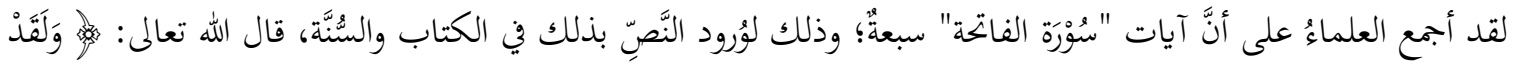

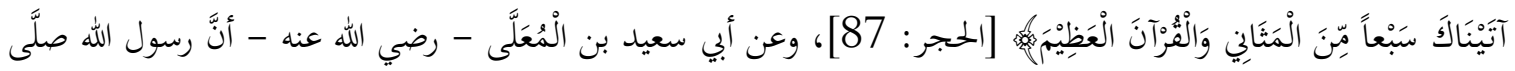

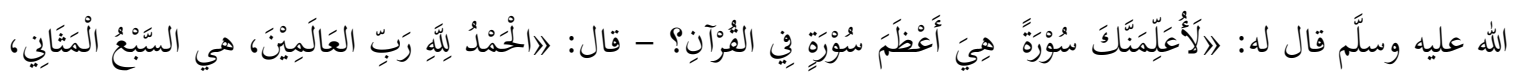

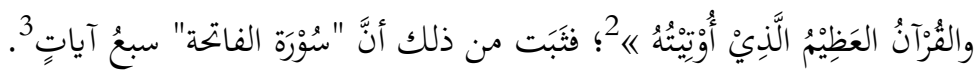
المبحث الثاني: أسماءُ "سُوْرَة الفاتحة" ووُجُجوْهُ التسمية بها:

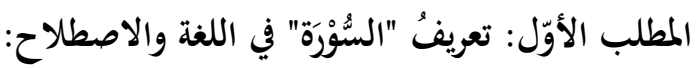

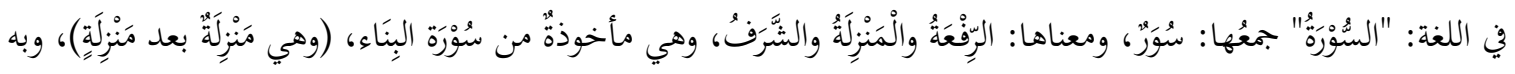

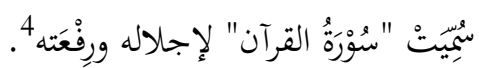

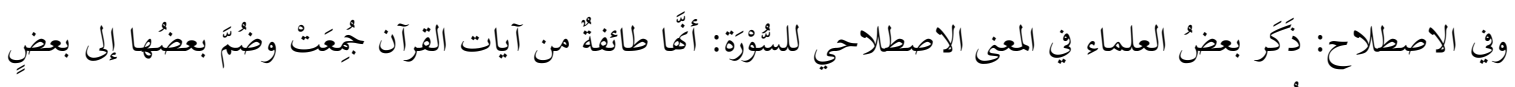

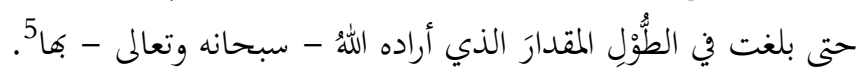

المطلب الثاني: أسماءُ "سُوْرَة الفاتحة" ووُجُجوْهُ التسمية بها:

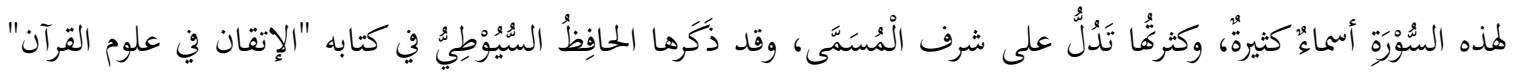

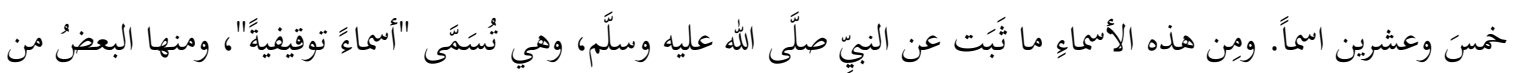

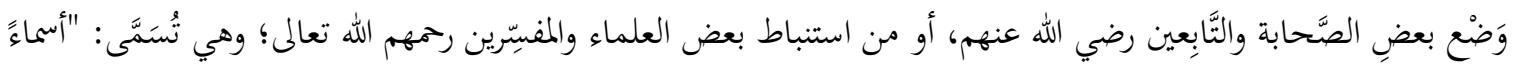

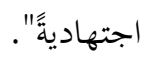

وإليكم تعريفَ أسماء هذه السُوْرَة من التوقيفية والاجتهادية مع بيان وُوجُوْهِ التسميةٍ لها.

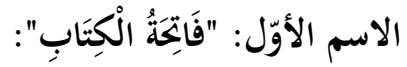

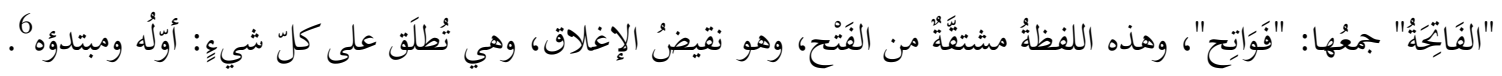

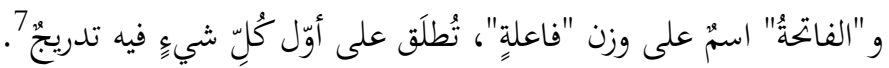

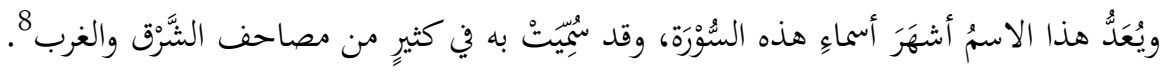

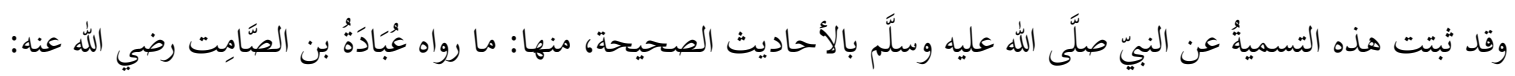




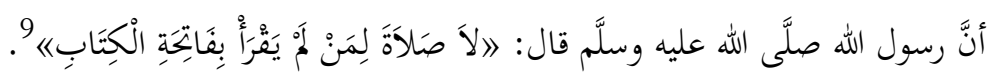

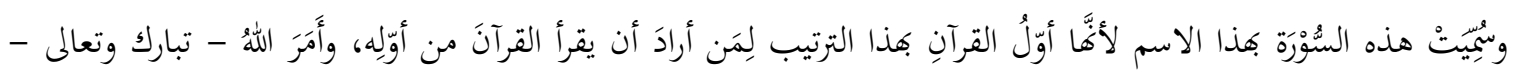

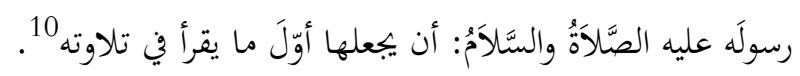

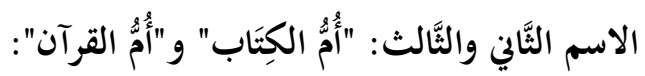

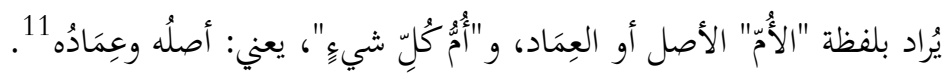

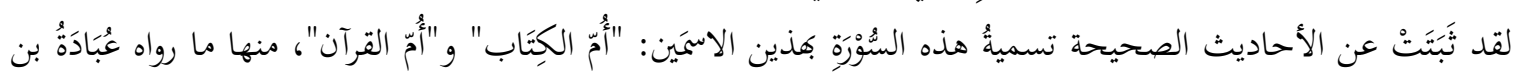

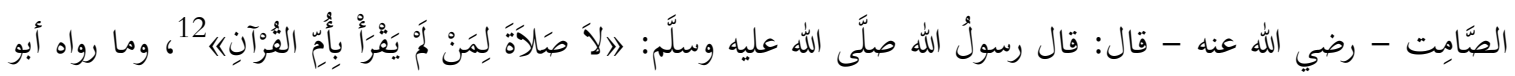

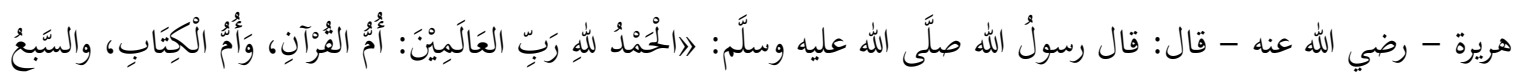

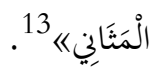

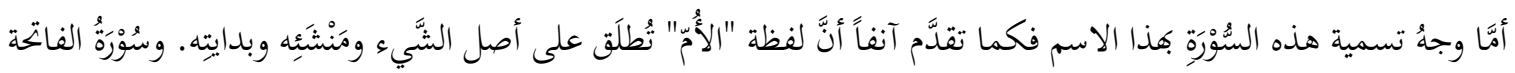

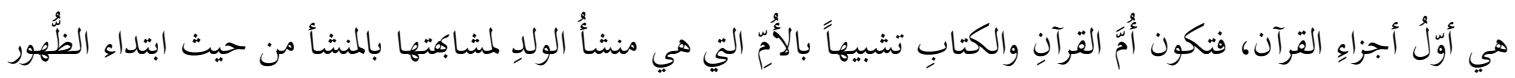
والوجود 14.

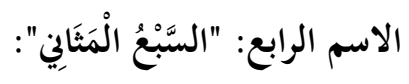

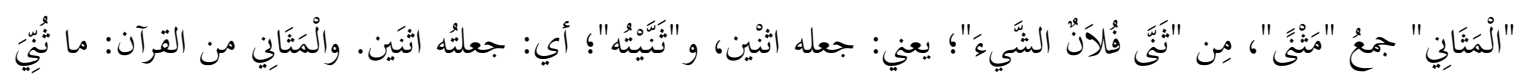
منه مَرَّة بعد مَرِّة 15.

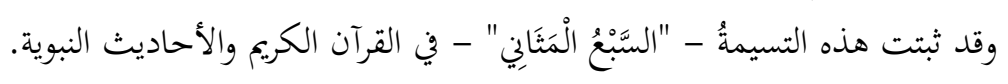

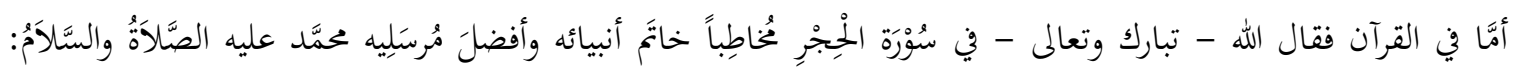

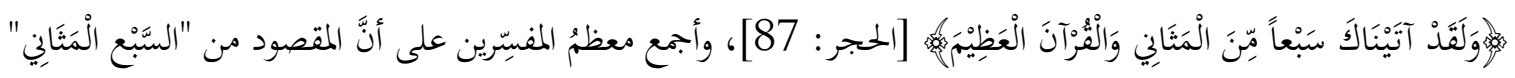

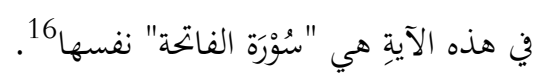

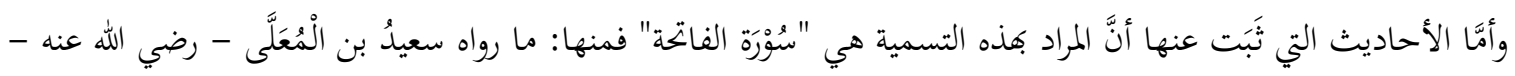

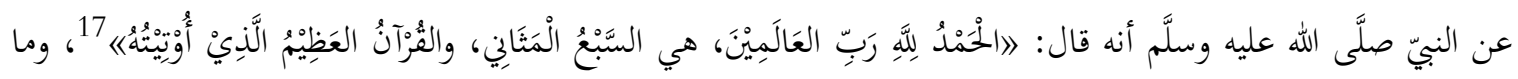

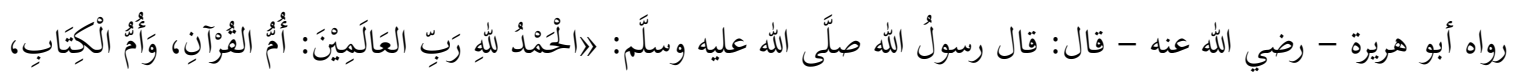

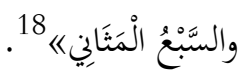

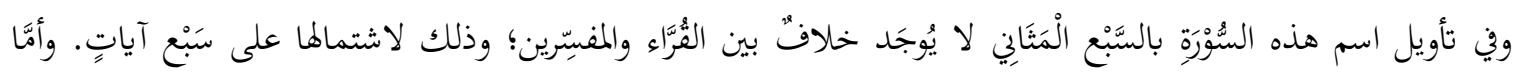

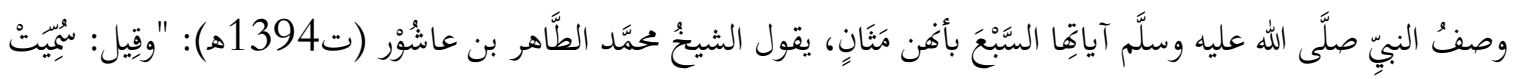

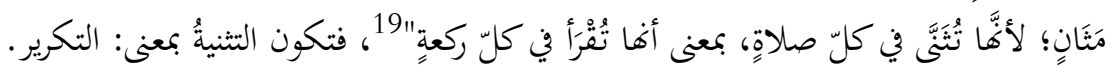




\section{الاسم الحامس: "القُرْآنُ العَظِيْمُ":}

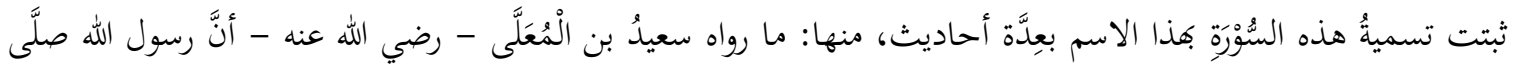

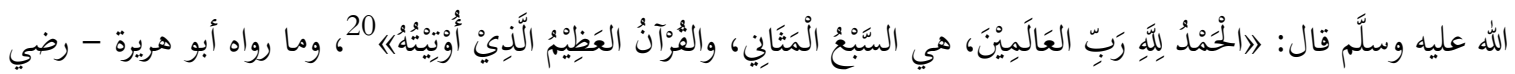

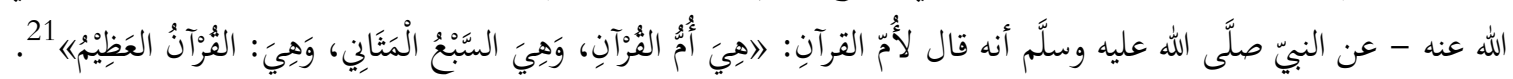

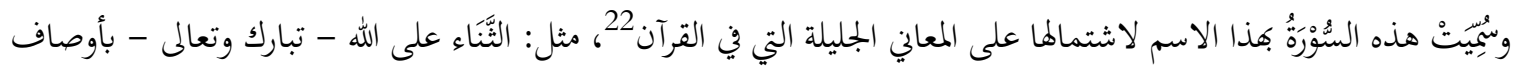

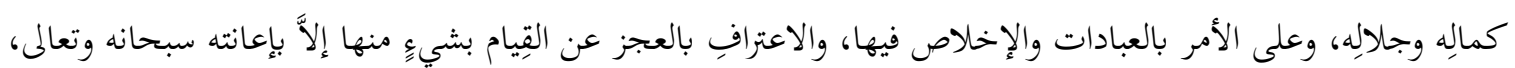

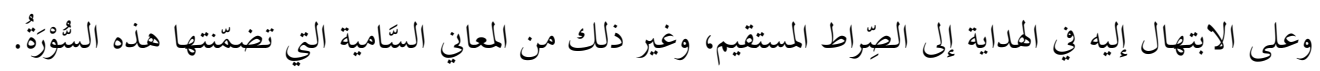

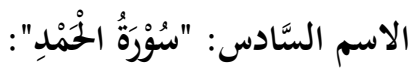

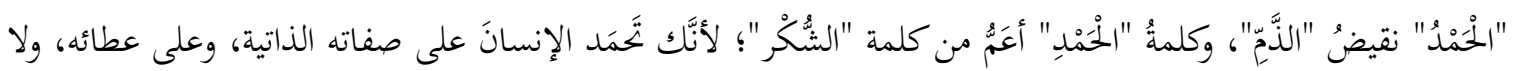
تشكره على صفاته 23.

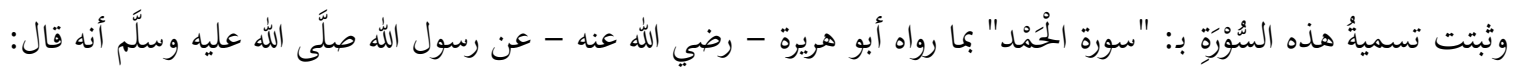

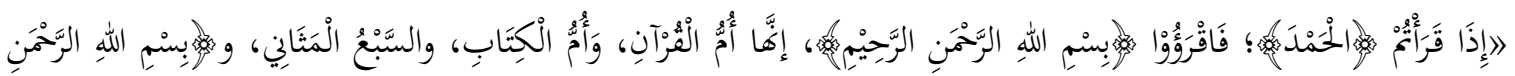

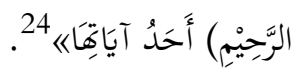

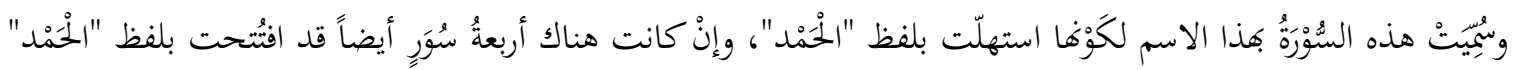

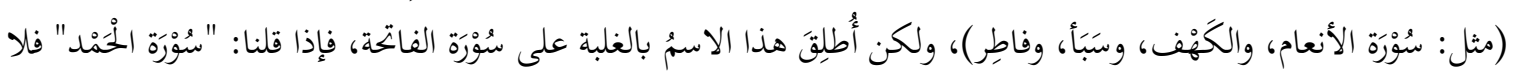
يتبادر إلى الأذهان إلأَ هذه السُوْرَة.25.

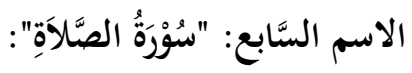

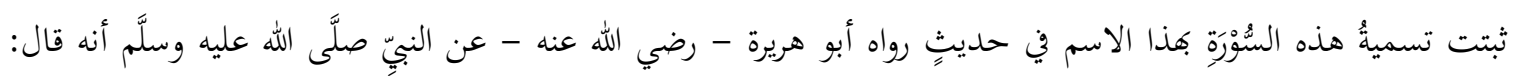

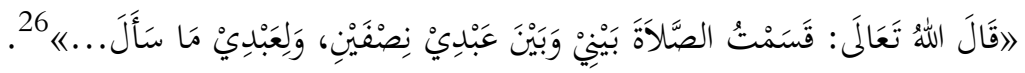

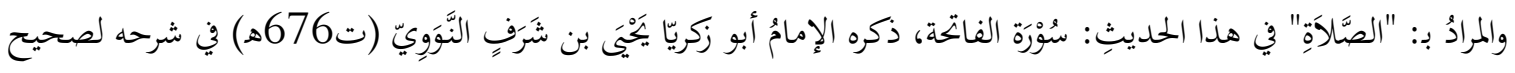
مسلم 27

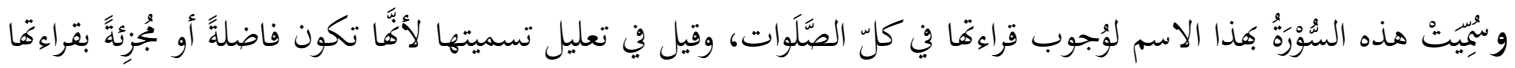

هذه سبعةُ أسماءٍٍ توقيفِة مشهورةٍ لسُورَة الفاتحة، والتي قد ثبتت عن النبيّ صلَّى الله عليه وسلَّمَ بأحاديث صحيحة.

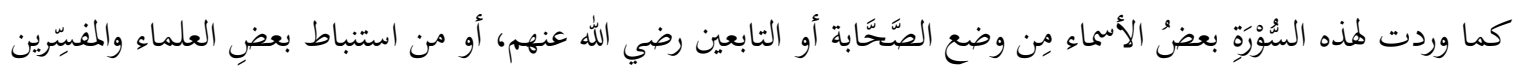

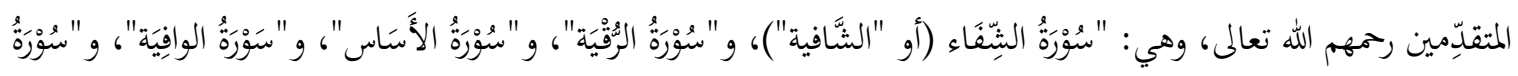

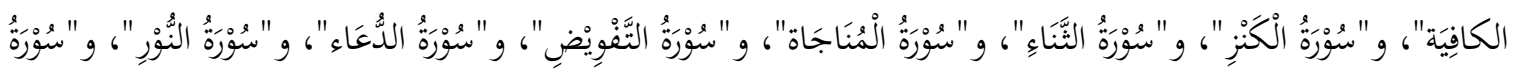




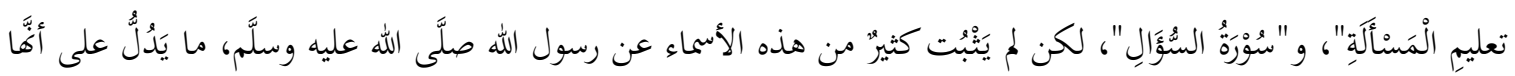

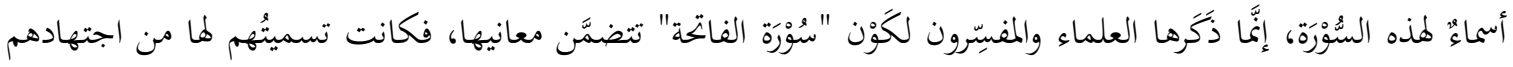

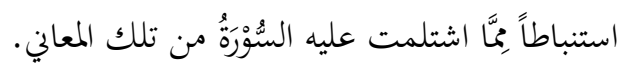

\section{المبحث الثالث: مَقَاصِدُ "سُوْرَة الفاتحة" وخصائصُهُها:}

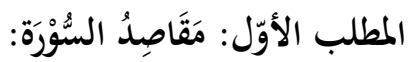

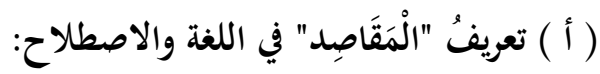

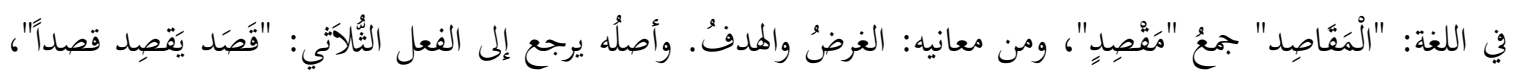
وقصدتُ الشيء؛ أي: طلبيُه بعينه 29.

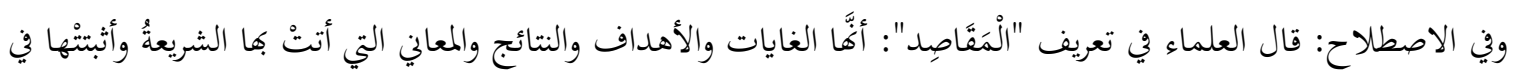

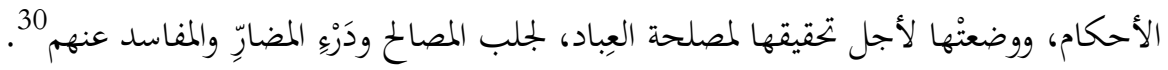

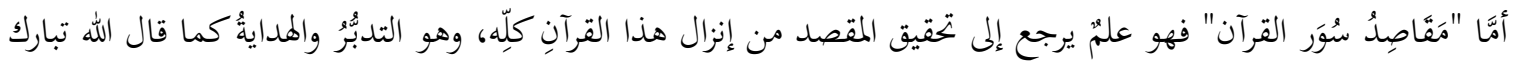

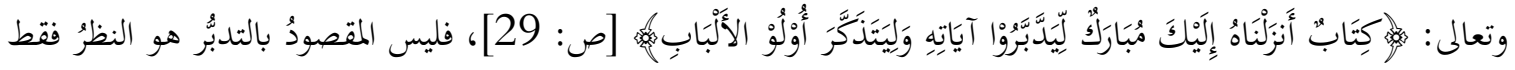

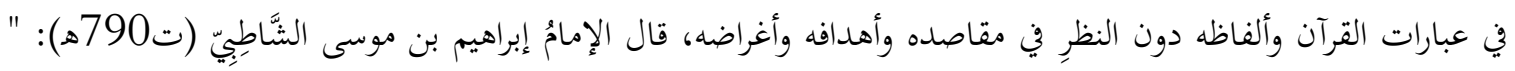

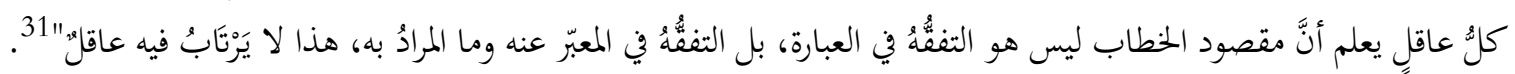

( ) مَقَاصِدُ "سُوْرَة الفاتحة":

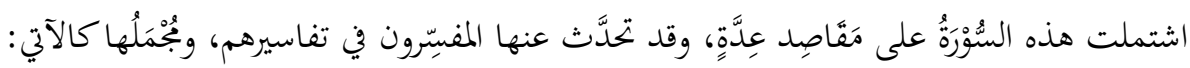

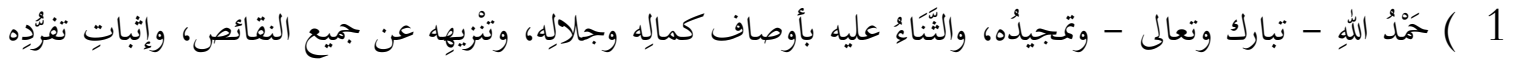

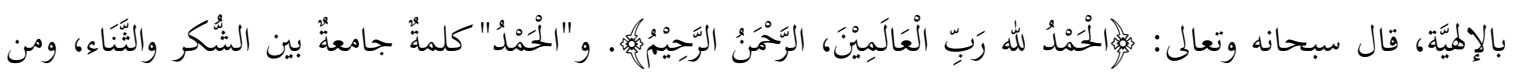

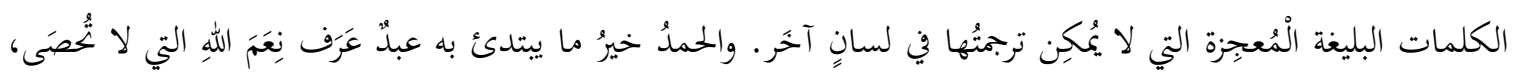

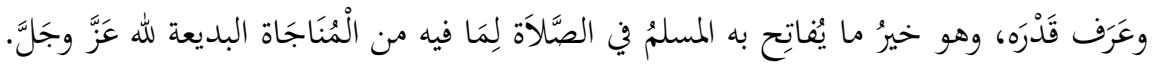

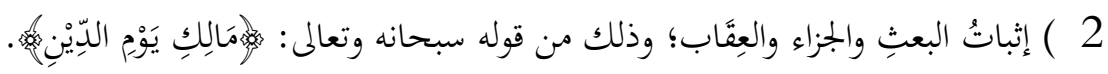

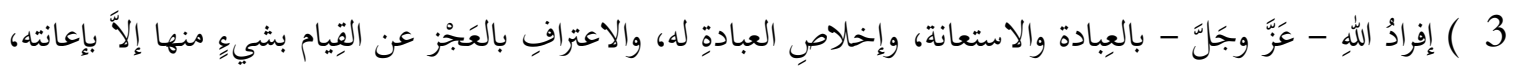

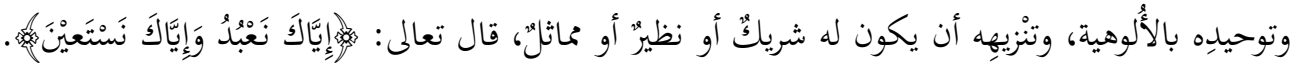

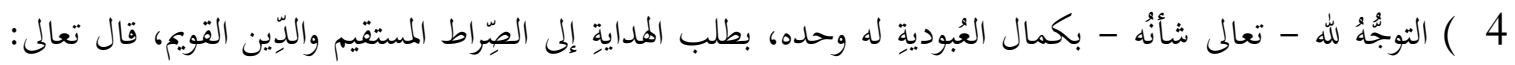

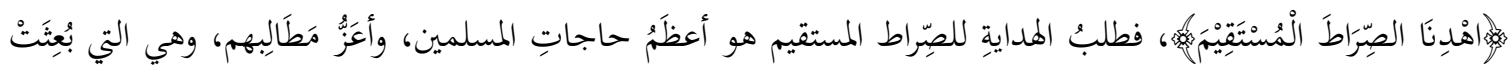

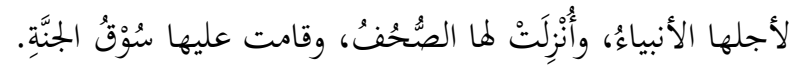

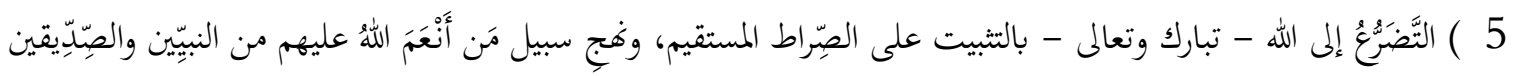




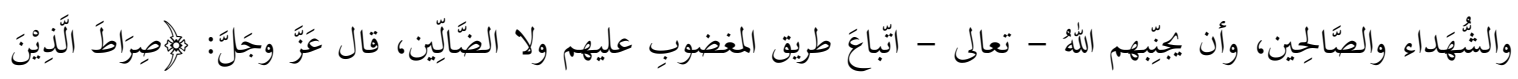

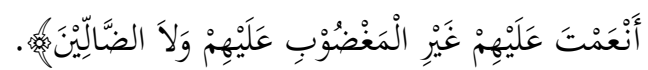

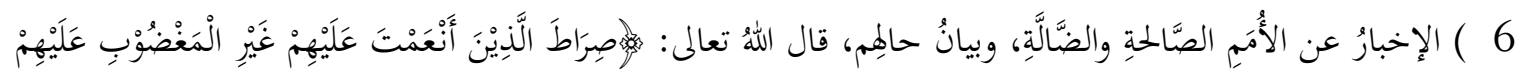

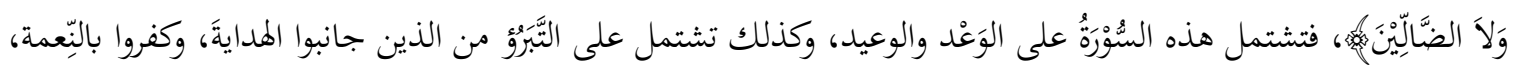

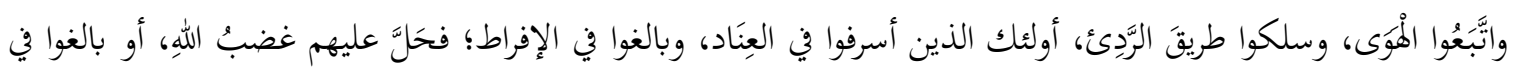

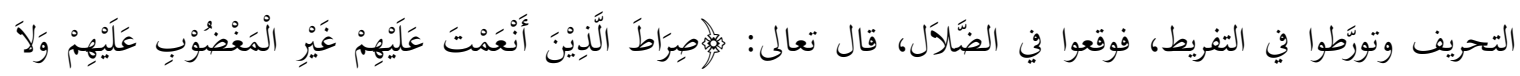

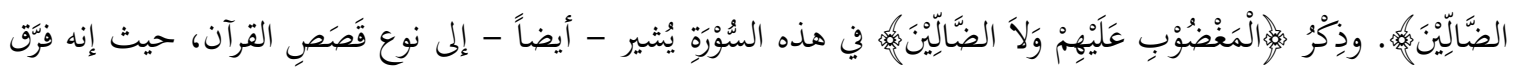

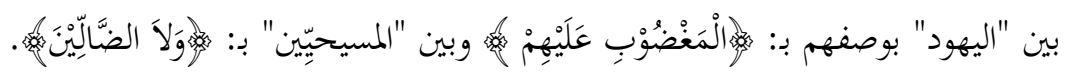

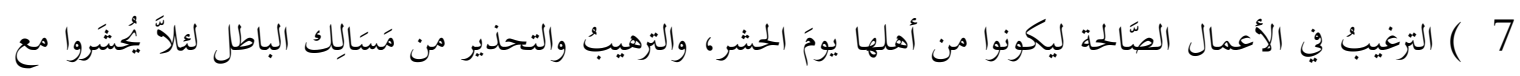

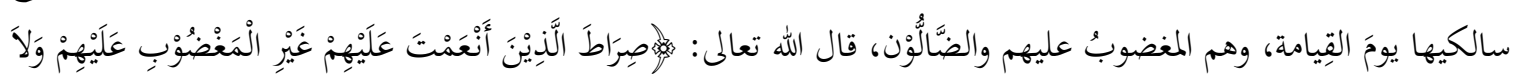
الضَّالِيْنَ 32.

المطلب الثاني: خَصَائصُ "سُوْرَة الفاتحة":

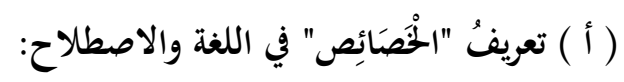

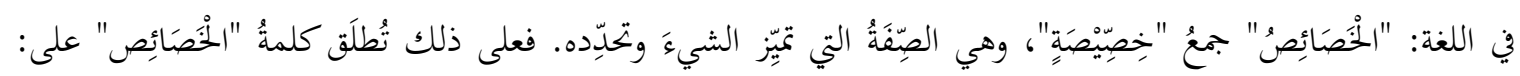

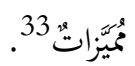

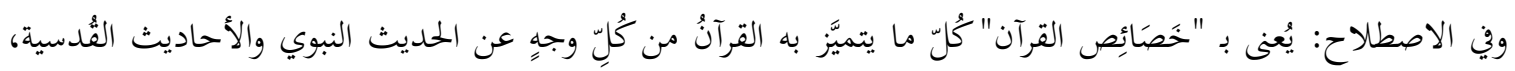

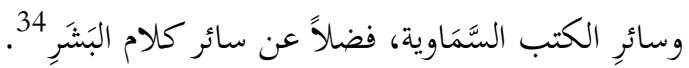

$$
\begin{aligned}
& \text { ( ب ) خَصَائيُصُ السُوْرَة }
\end{aligned}
$$

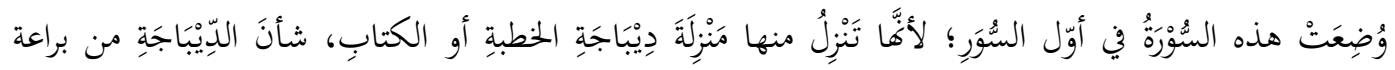

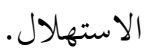

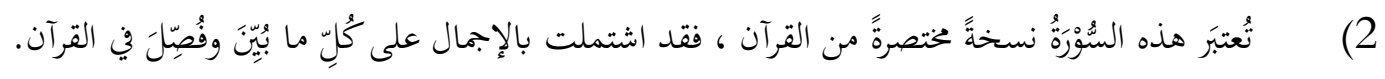

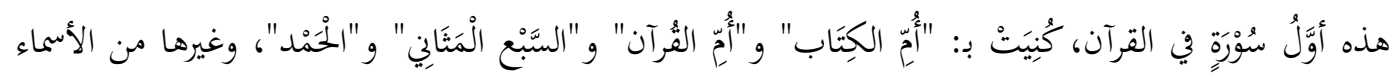

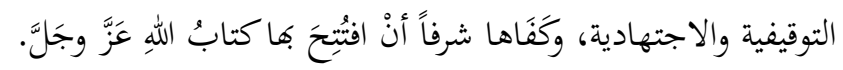

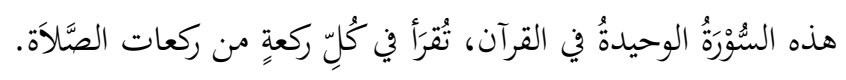

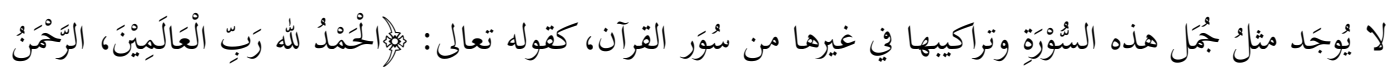

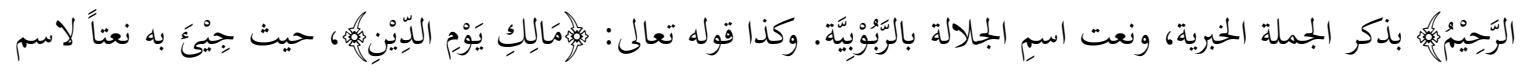

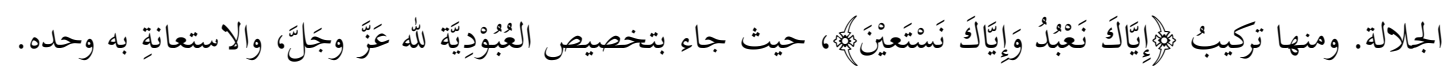


هذه السُوْرَةُ الوحيدةُ في القرآن، التي تشتمل على معاني آياتِهِ كُلِّها، وتشتمل على أنواع التوحيد الثَّلاثة: الألُؤهِيّة

والرُبُوبِبيَّة والأسماء والصِّفَّات.

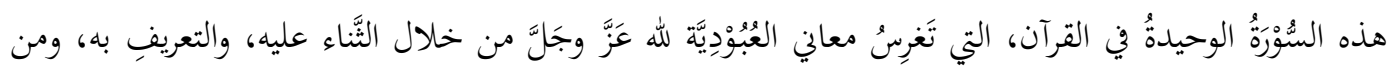

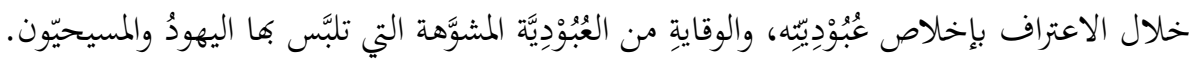

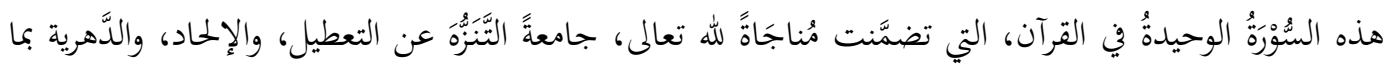

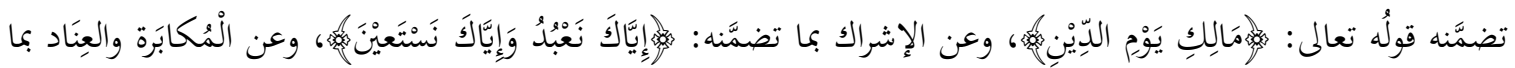
تضمَّنه:

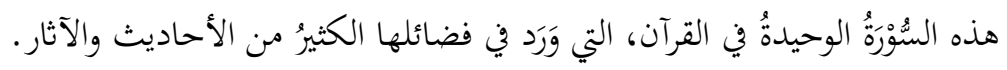

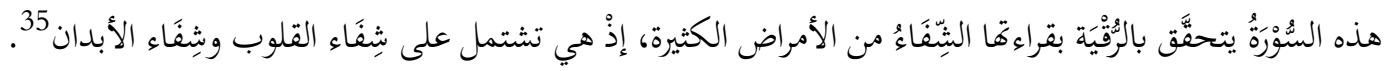

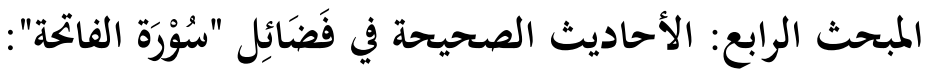

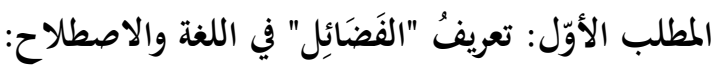

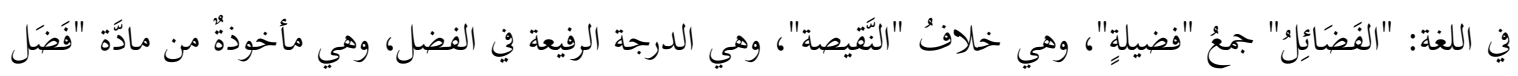

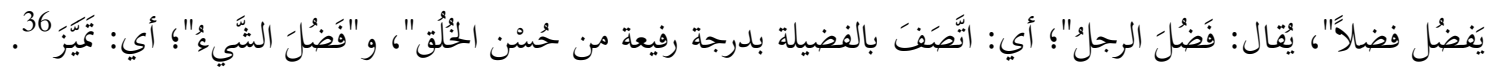

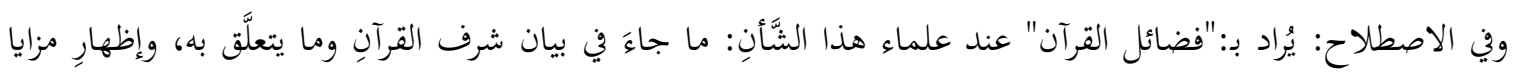

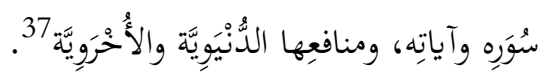

المطلب الثََّّي: الأحاديث الصحيحة في فضائل "سُوْرَة الفاتحة":

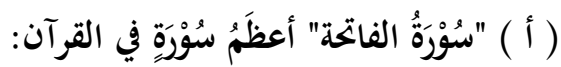

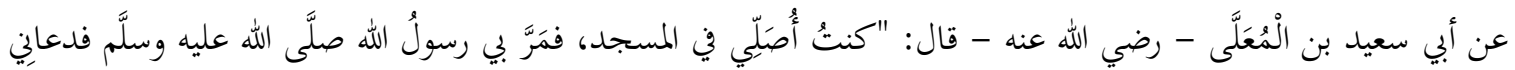

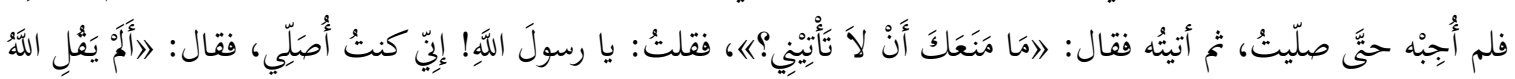

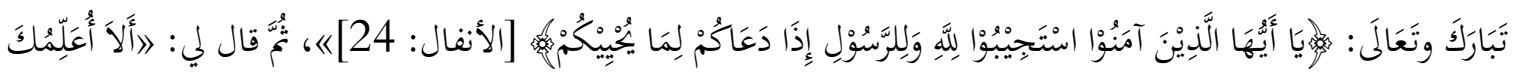

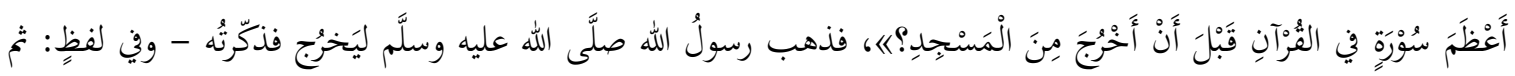

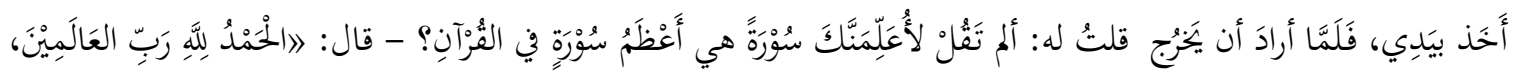

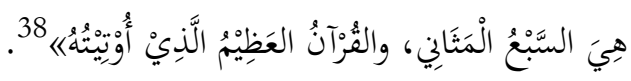

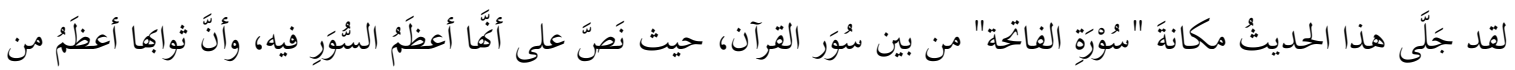

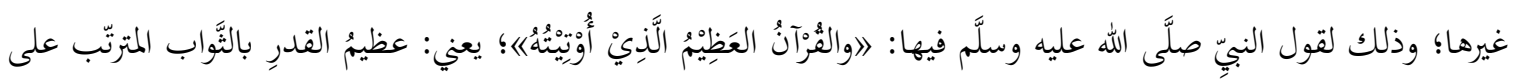

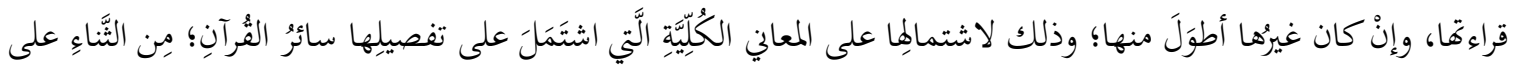

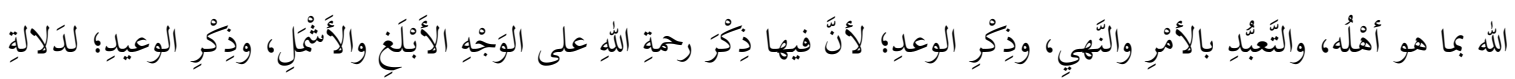




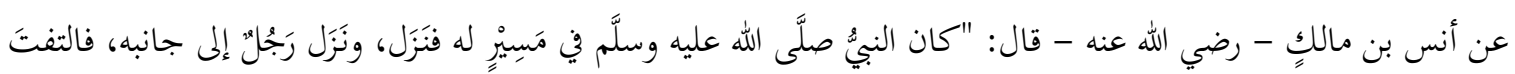

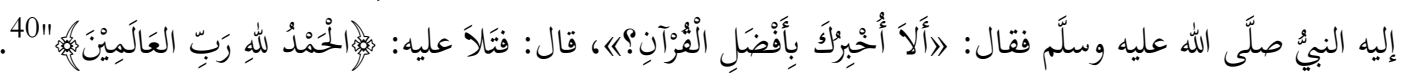

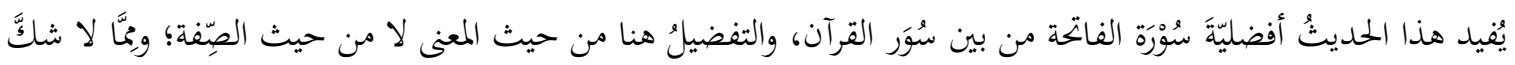

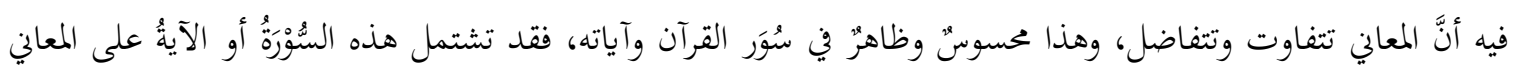

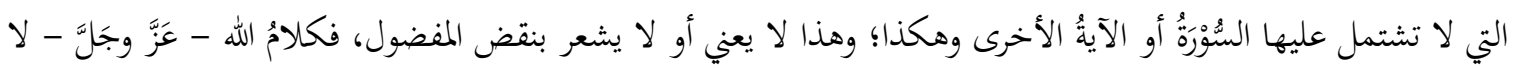

$$
\text { نقصَ فيه } 41 .
$$

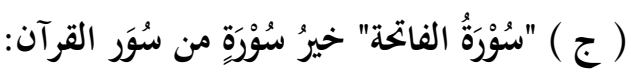

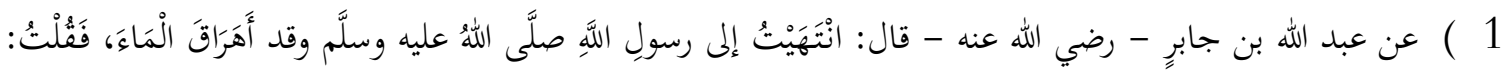

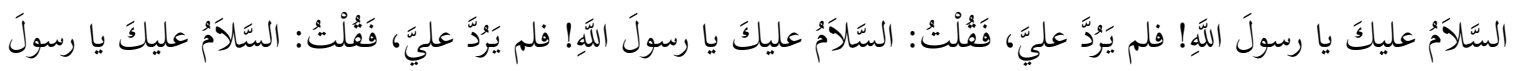

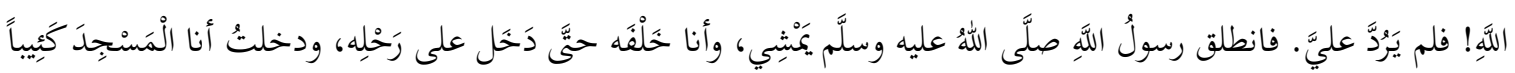

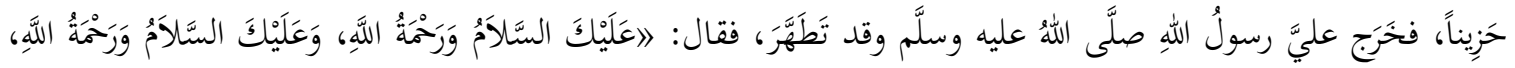

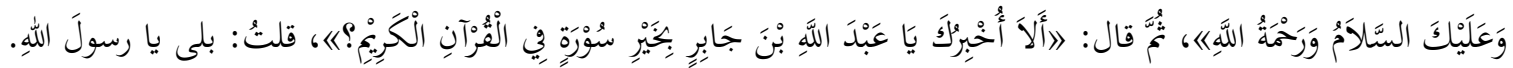

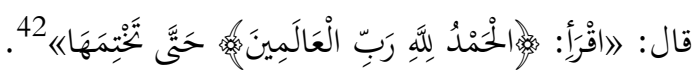

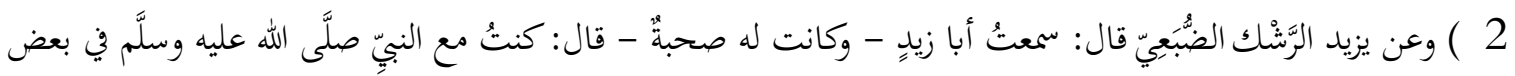

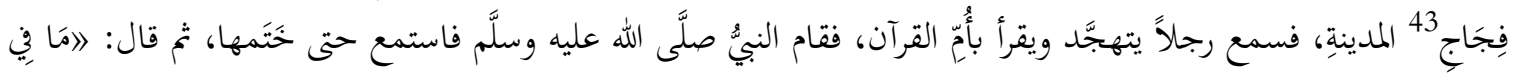

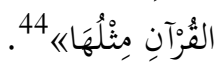

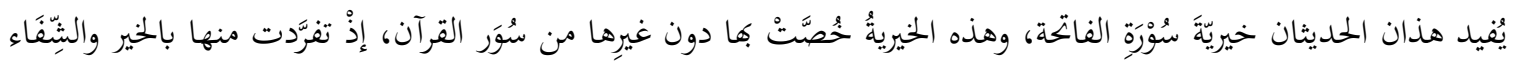
والأفضليّة أكثَر مِن غيرها؛ وذلك لاشتمالها على المعاني السَّامية الجليلة التي في القرآن من الثنّاء على الله تعالى، والتعبُّبِ بالأمر

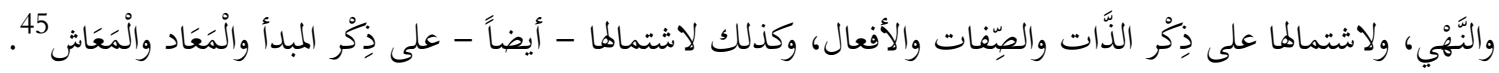

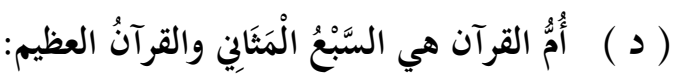

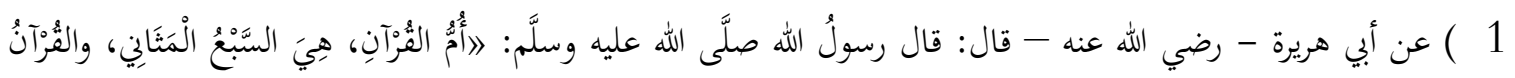

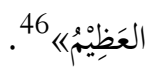

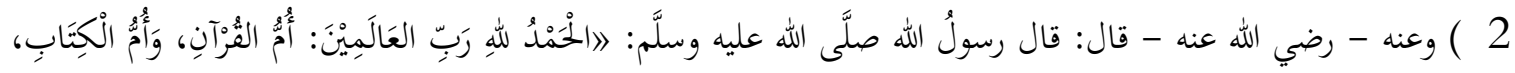

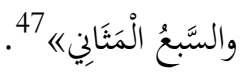




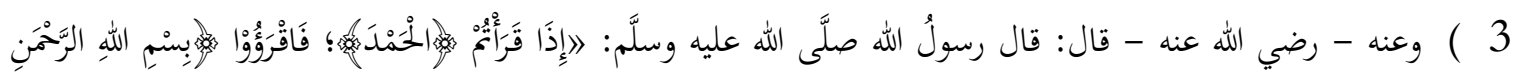

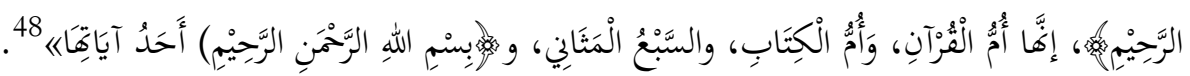

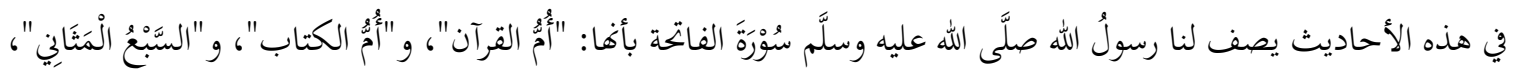

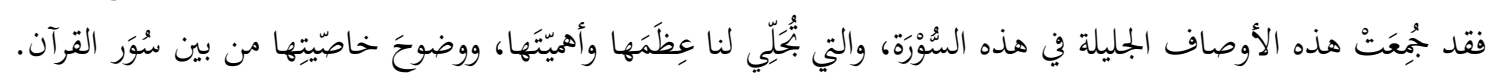

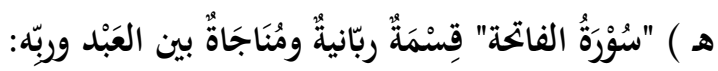

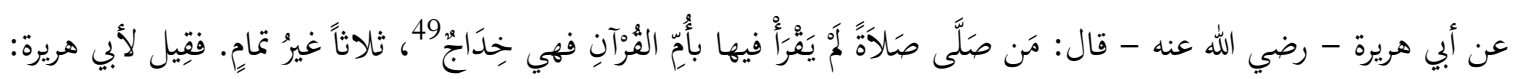

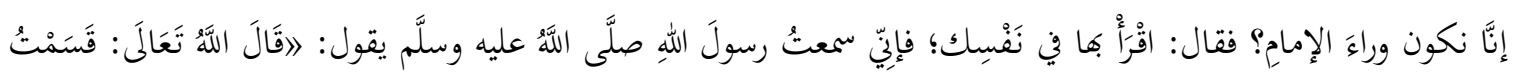

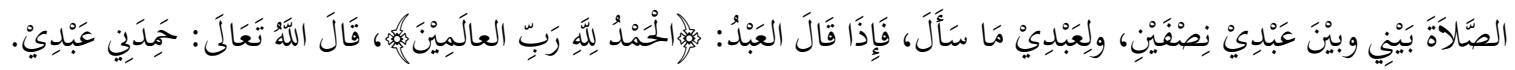

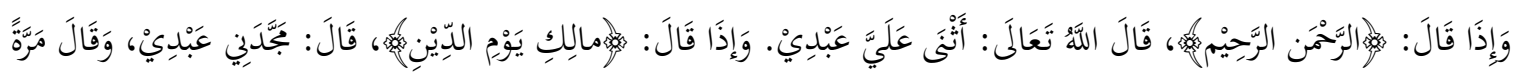

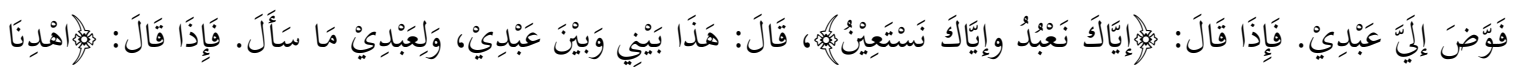

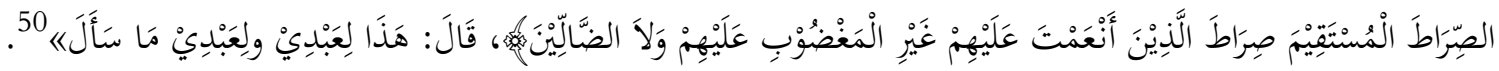

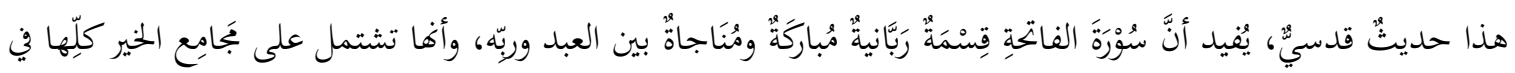

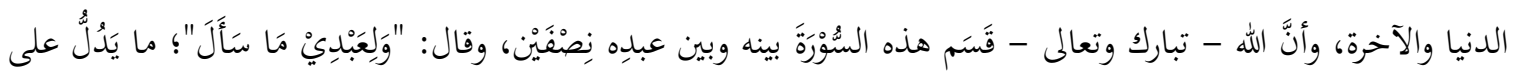

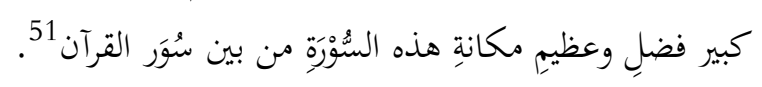

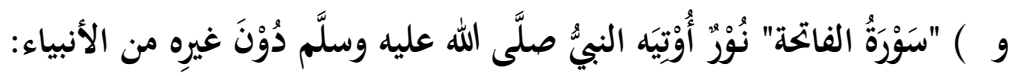

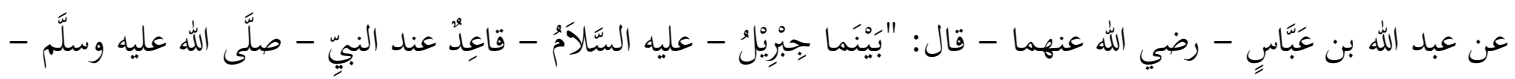

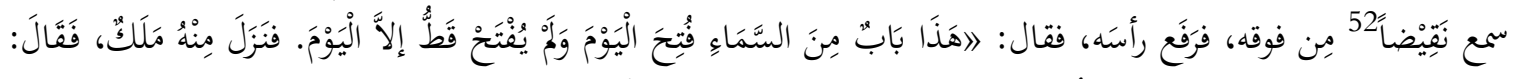

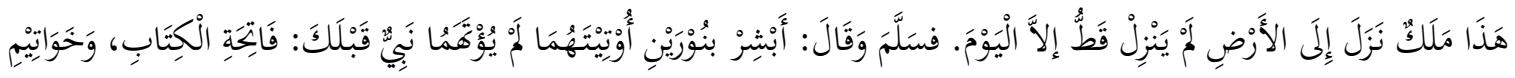

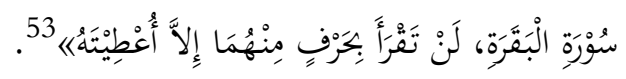

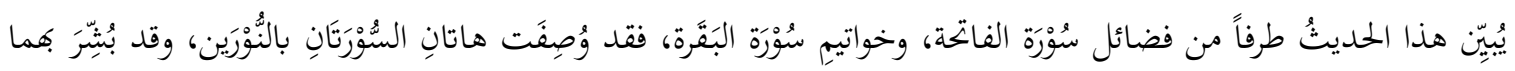

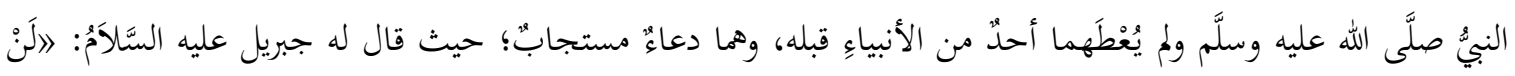

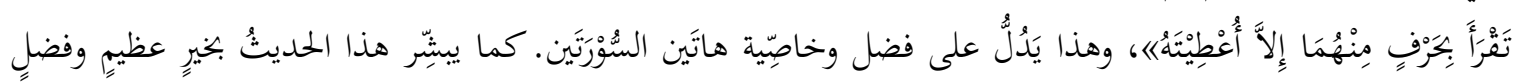

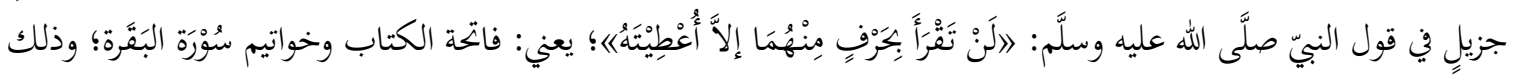
لاشتمالمها على عِظَم المعاني.

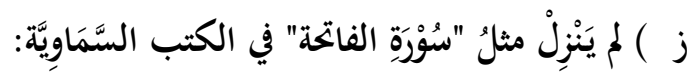

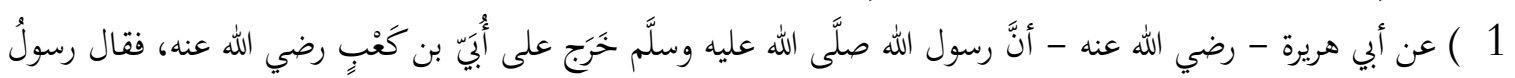

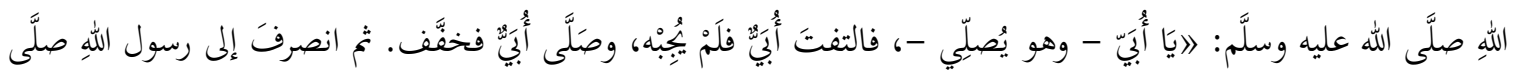




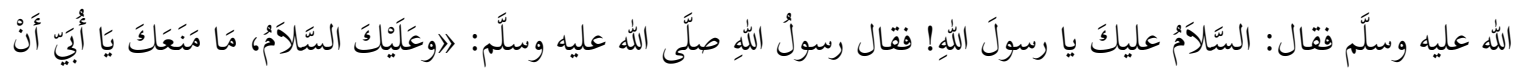

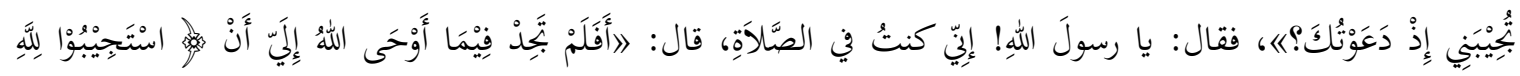

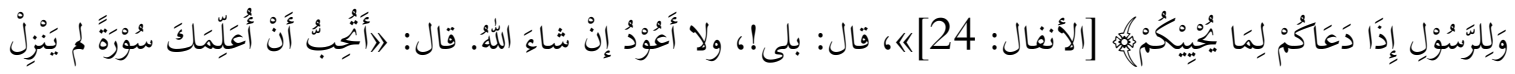

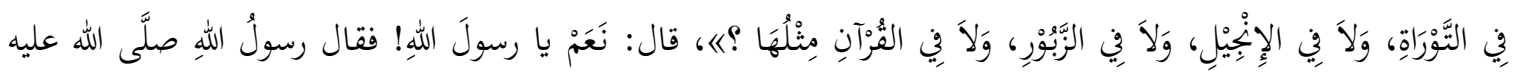

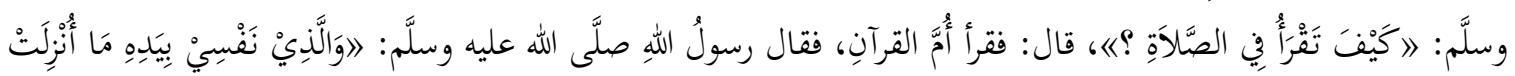

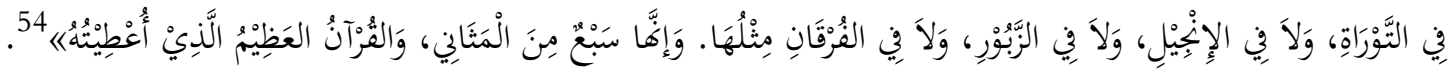

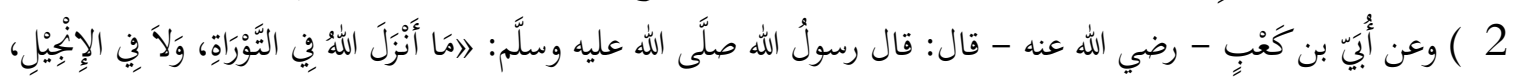

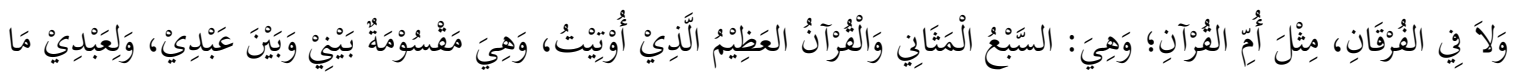
سَأَلَه 55.

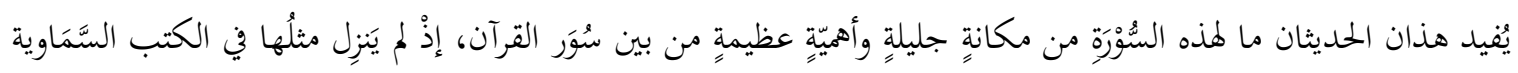

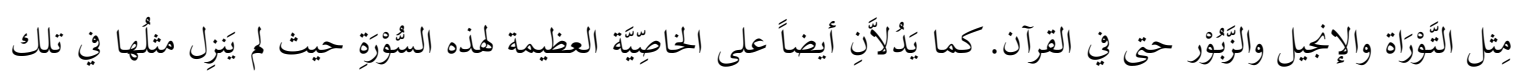

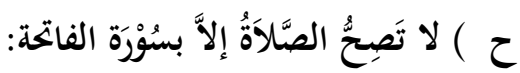

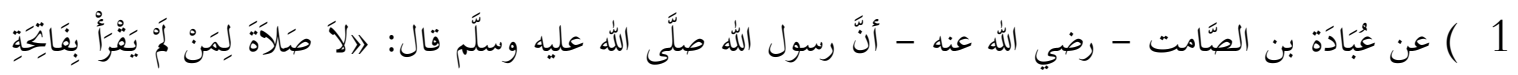

$$
\text { الْكِتَابِ《) }
$$

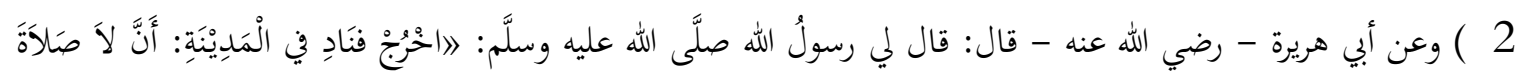

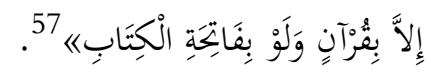

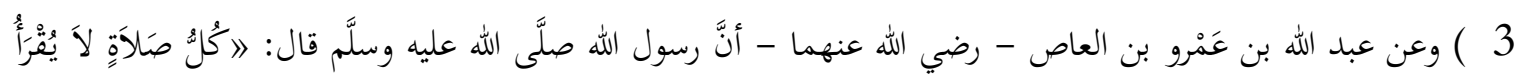

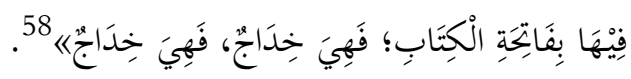

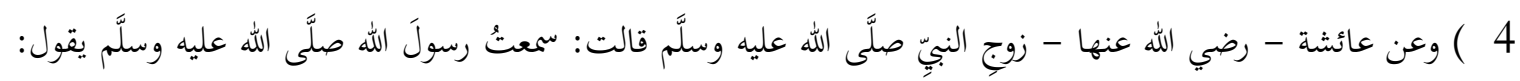

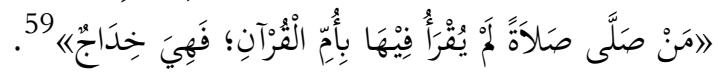

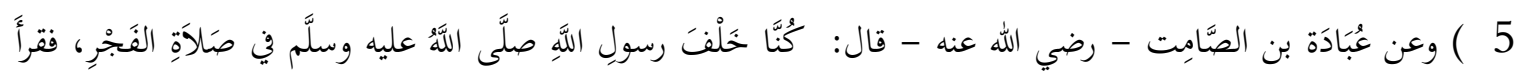

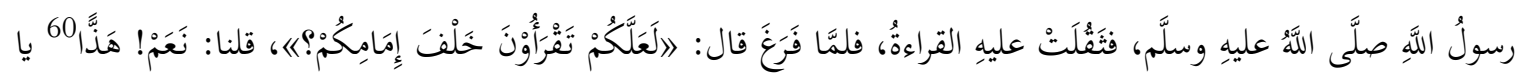

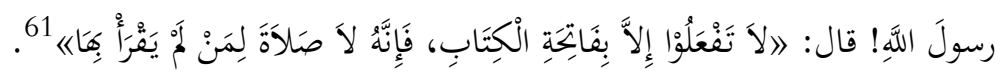

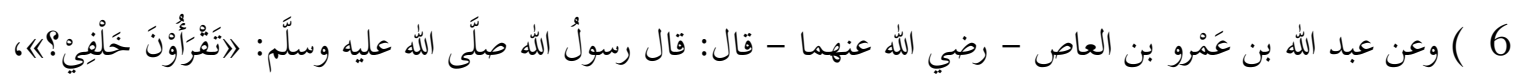

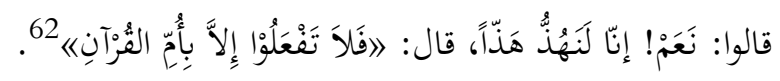

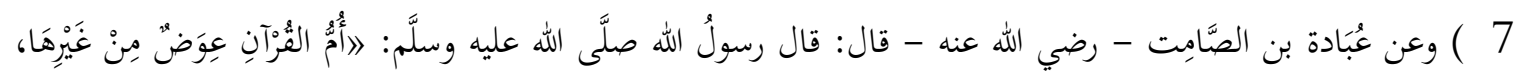




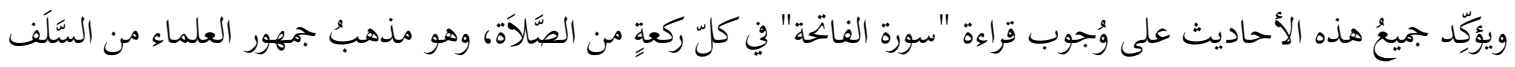

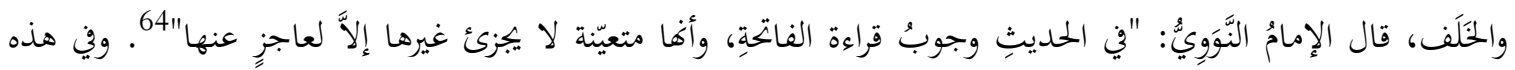

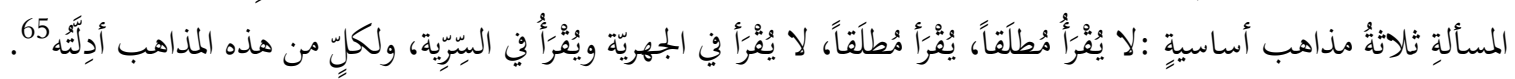

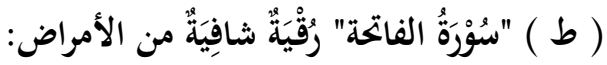

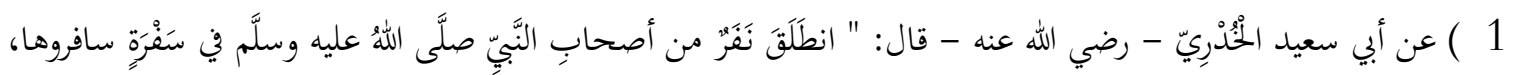

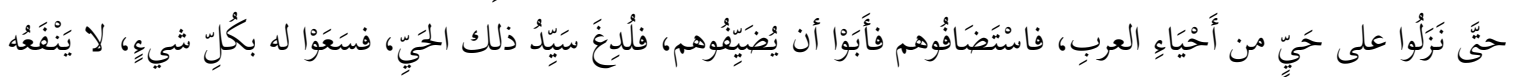

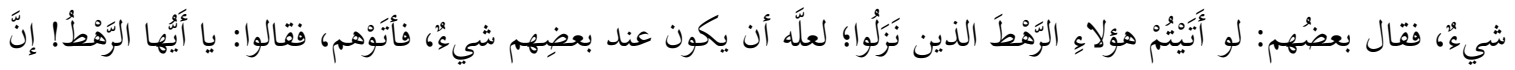

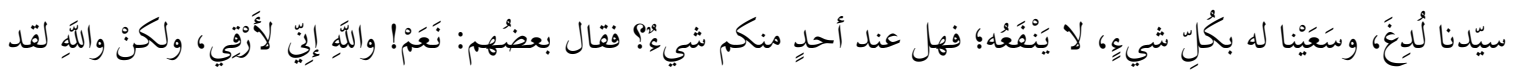

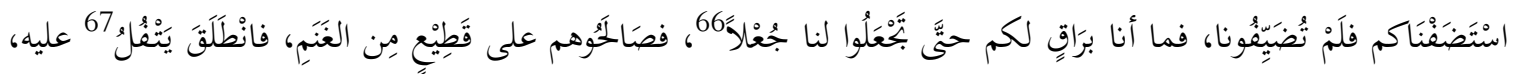

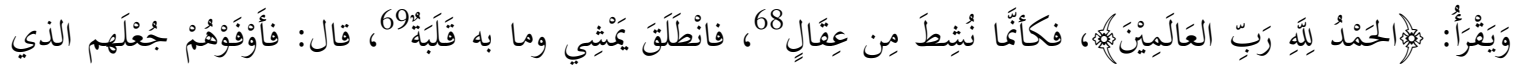

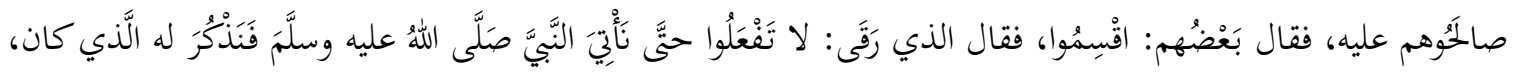

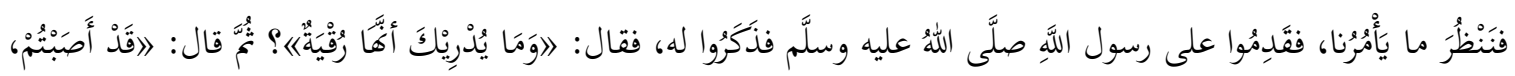

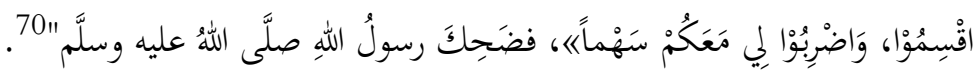

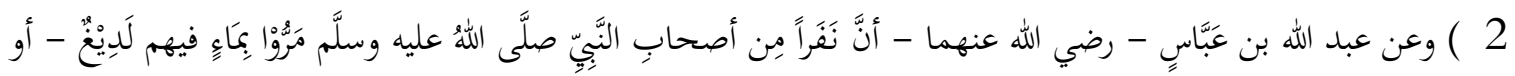

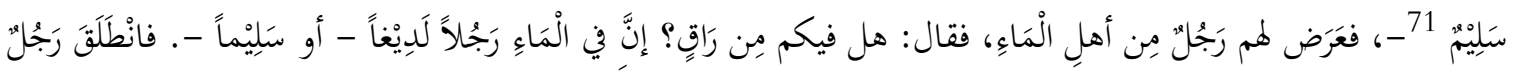

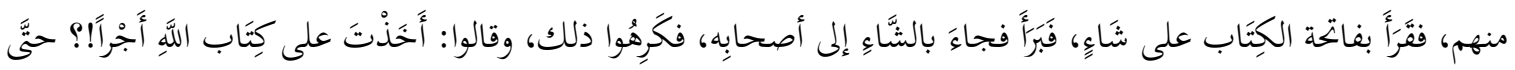

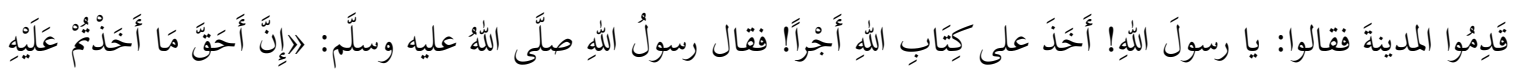

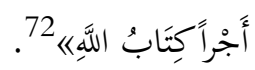

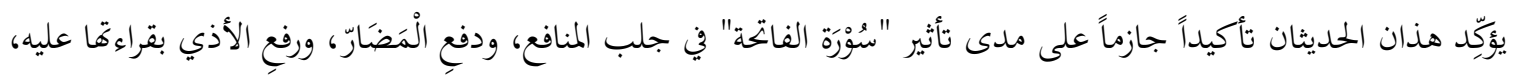

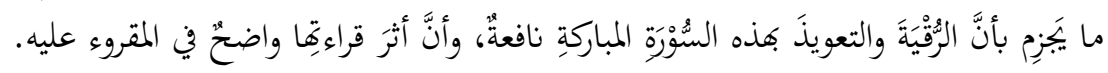

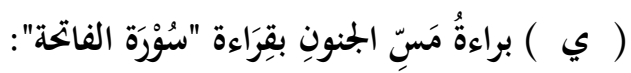

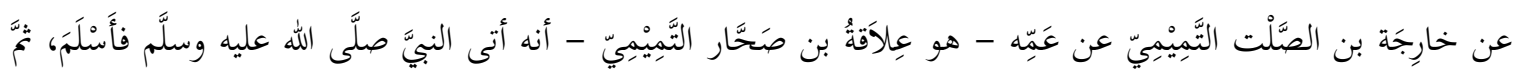

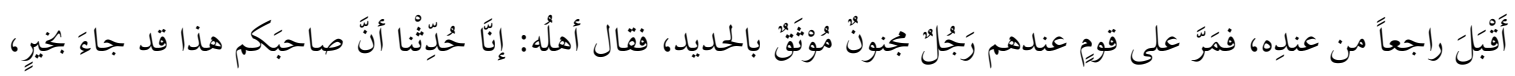

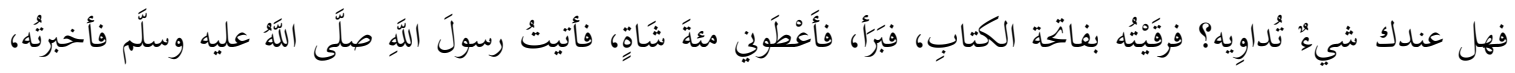

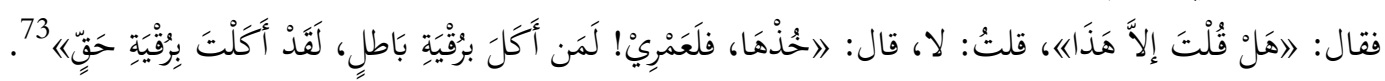

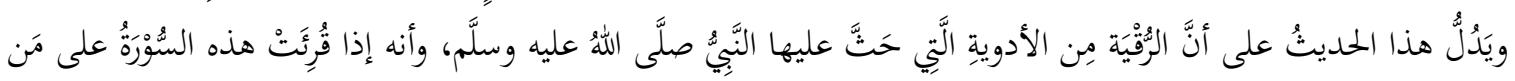




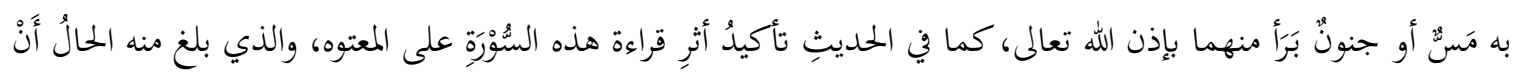

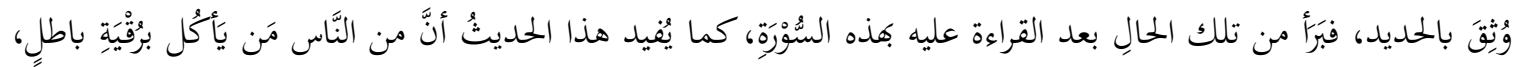

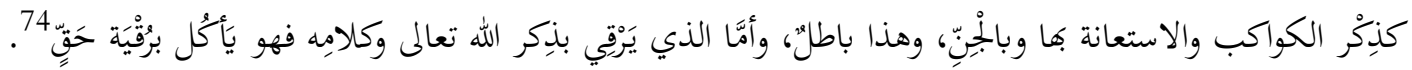

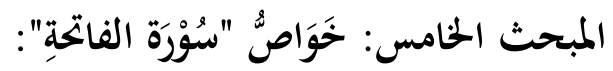

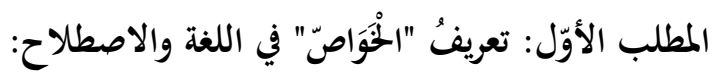

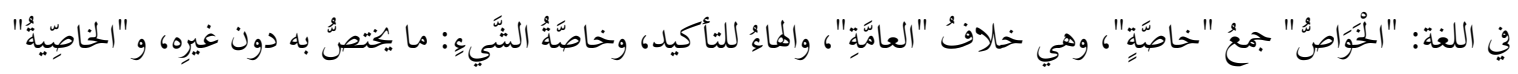
نسبةً إلى الخاصَّة 75.

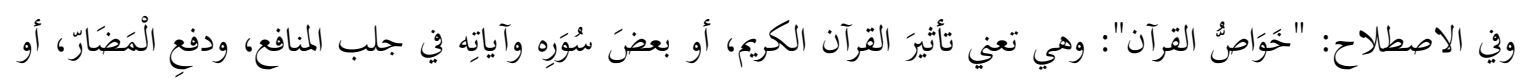

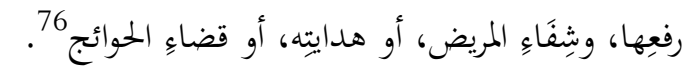

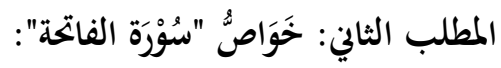

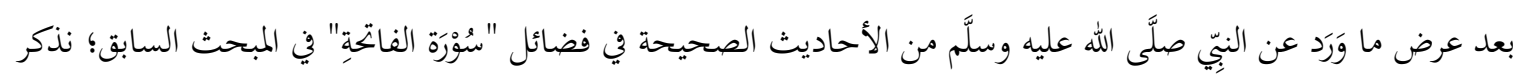

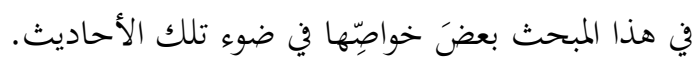

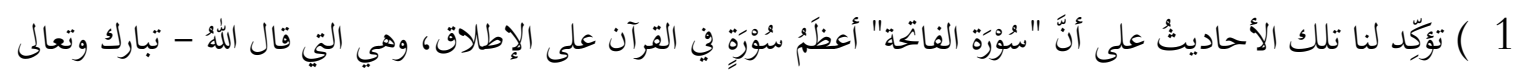

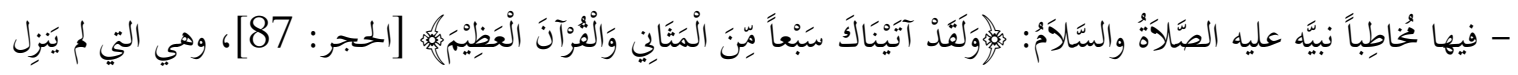

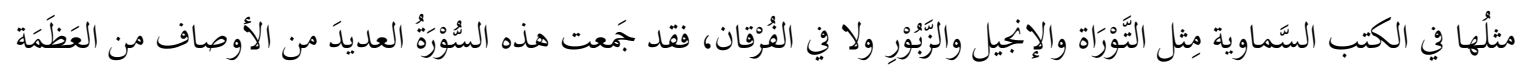

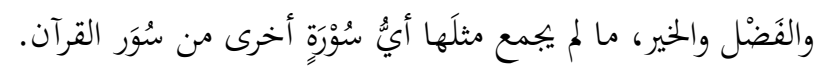

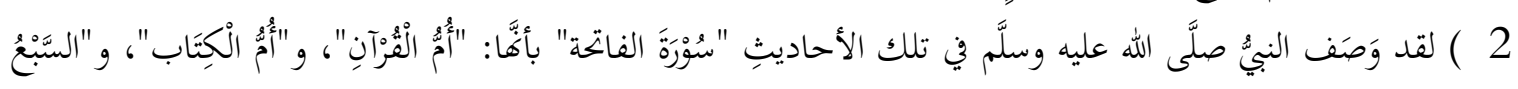

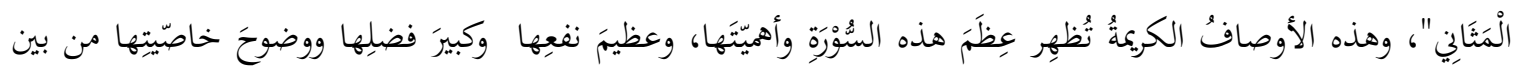

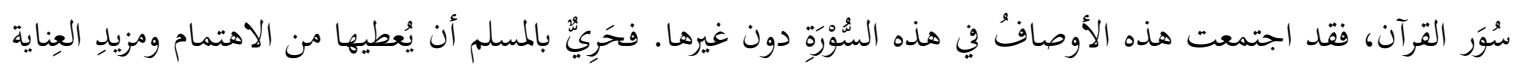

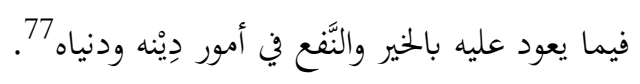

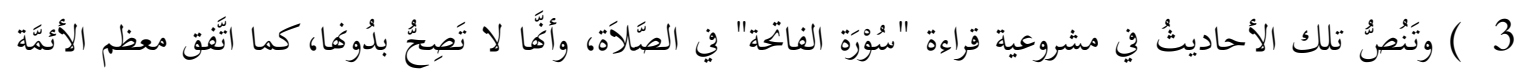

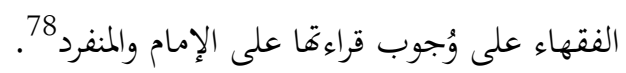

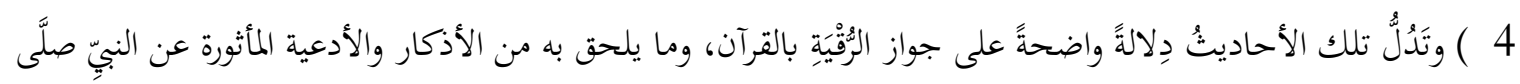

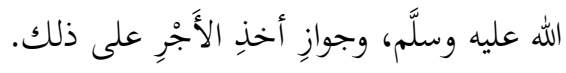

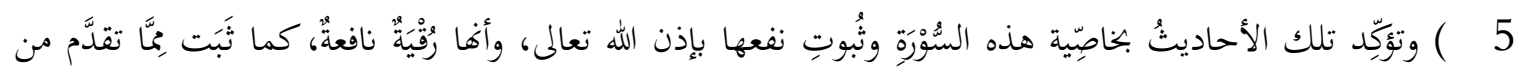

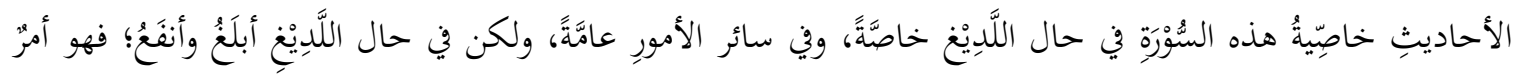

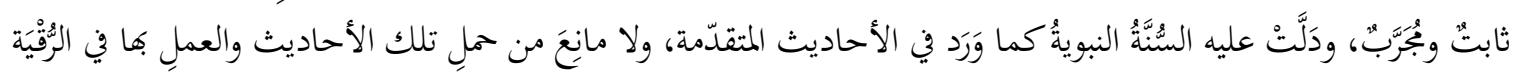




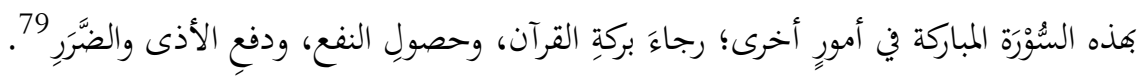

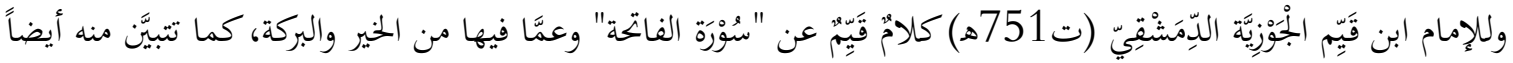

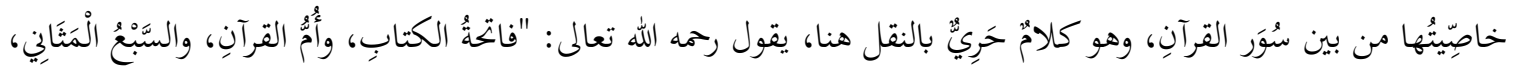

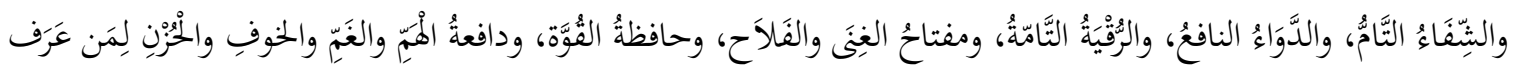

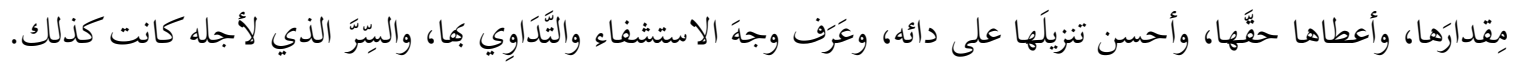

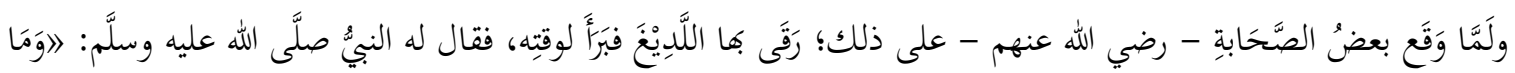

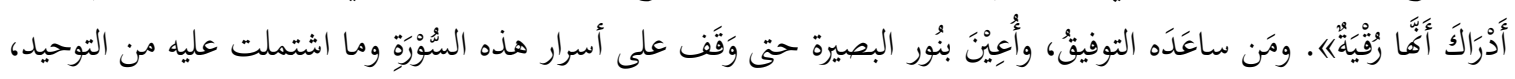

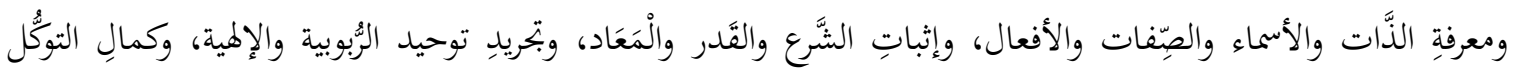

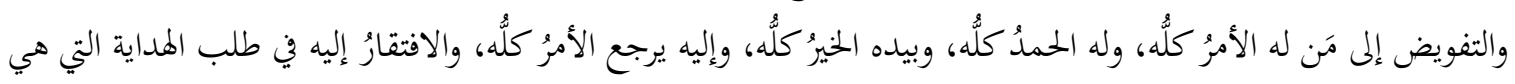

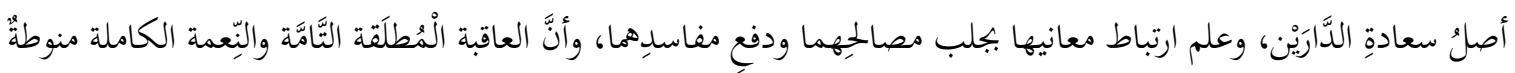

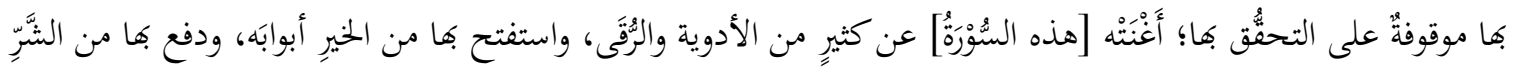
أسبابَه" 80

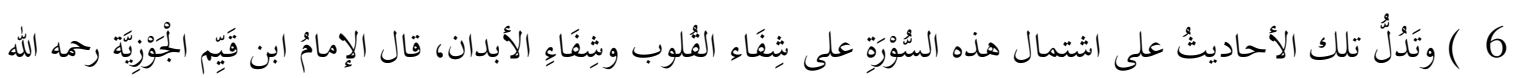

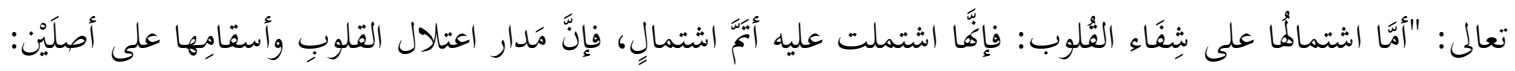

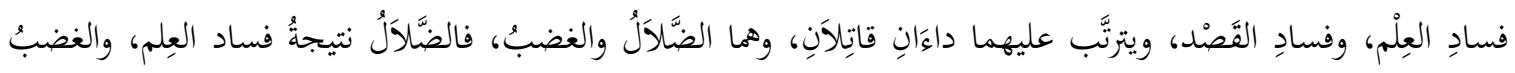

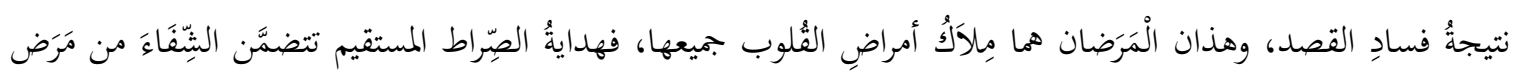

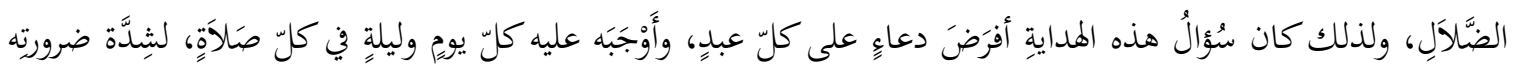

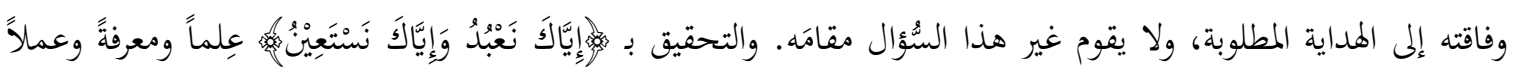

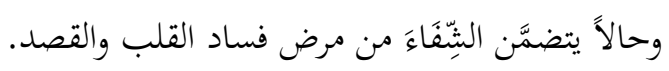

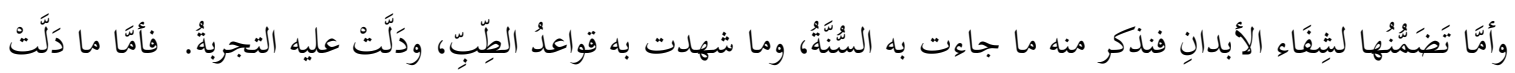

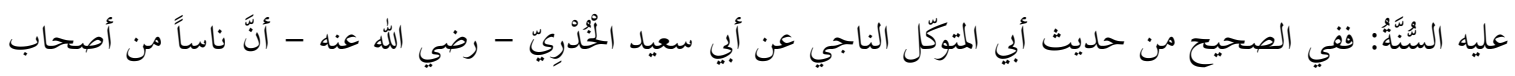

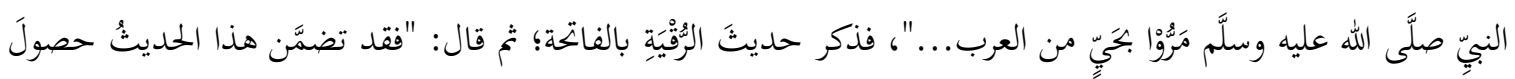

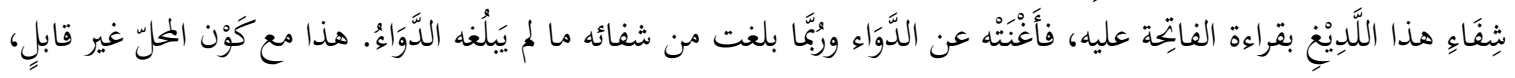

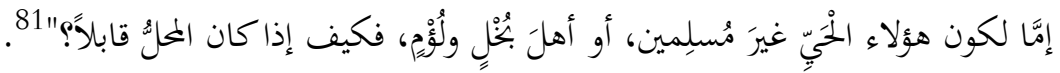

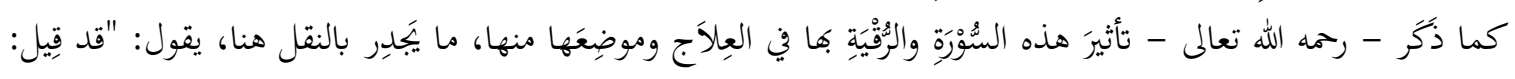

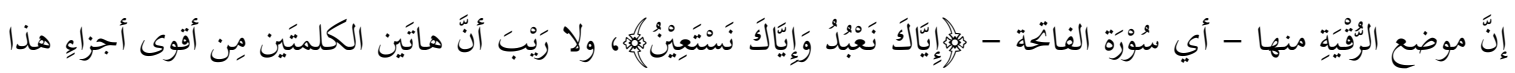

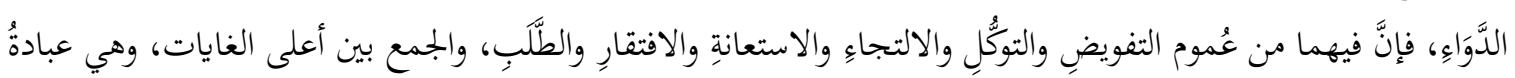




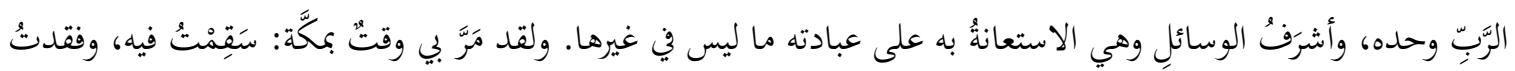

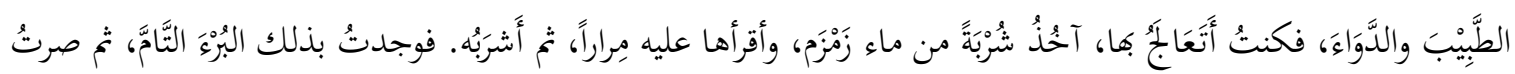

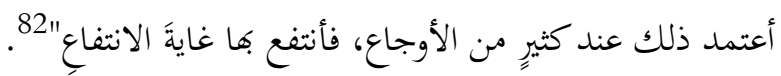

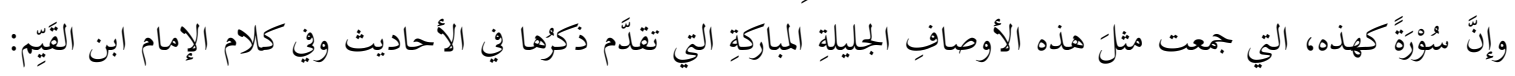

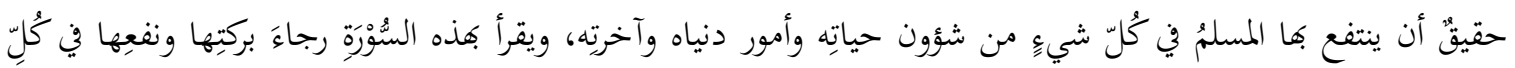

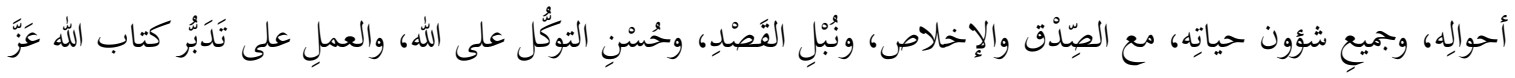

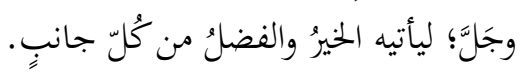

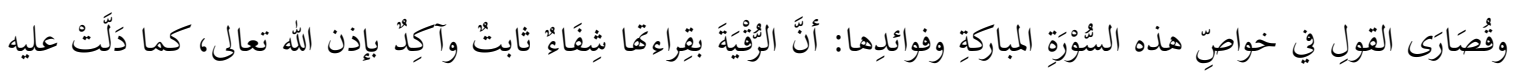
تلك الأحاديثُ الصَّحيحةُ.

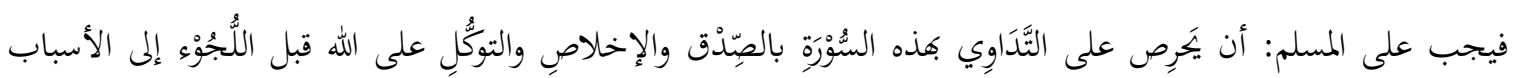

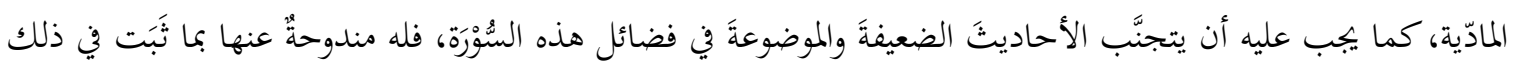
عن النبيّ صلَّى الله عليه وسلَّم بالأحاديث الصَّحيحة.

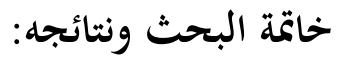

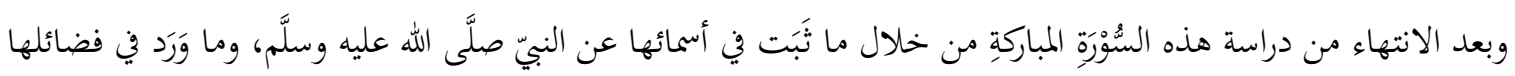

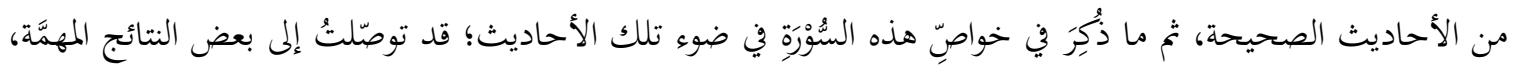

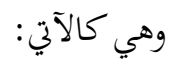

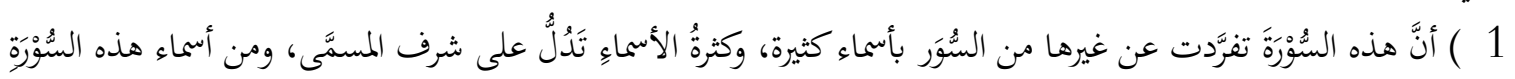

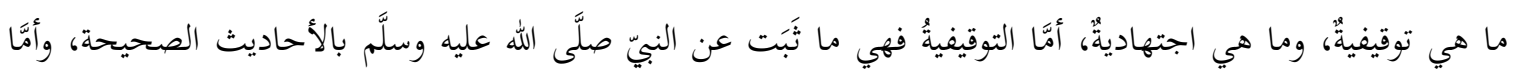

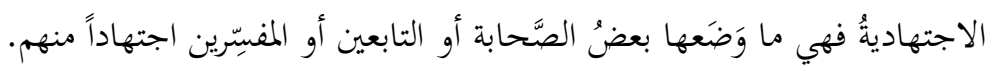

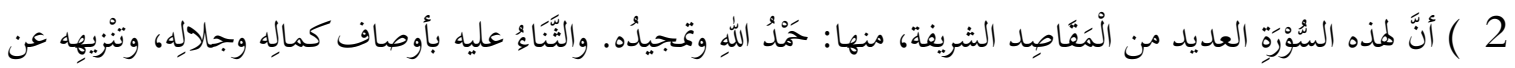

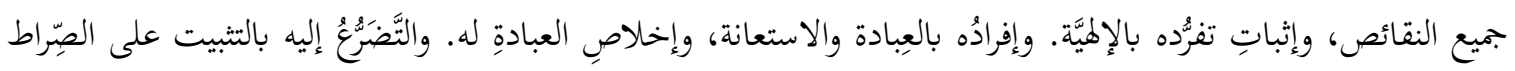

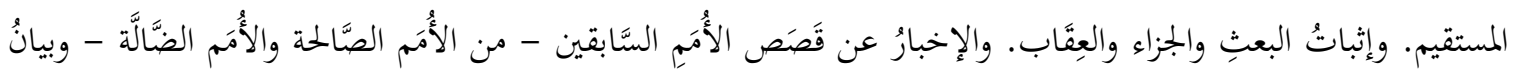

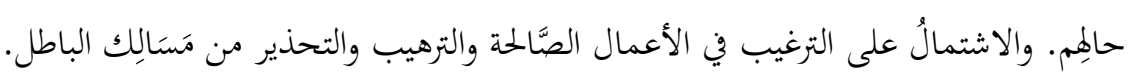

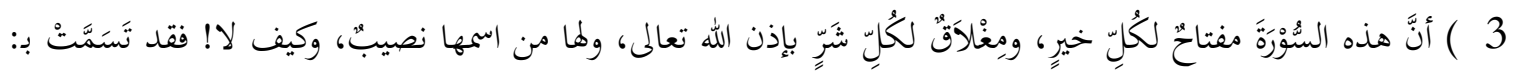
"الفاتحة".

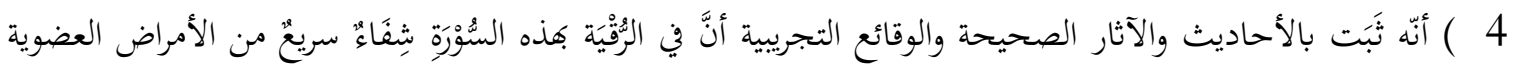
والنفسية. 


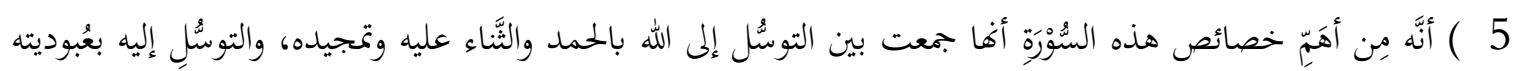

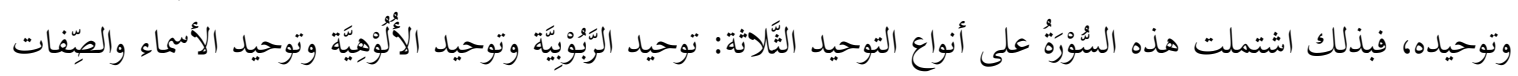

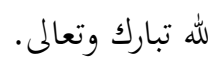

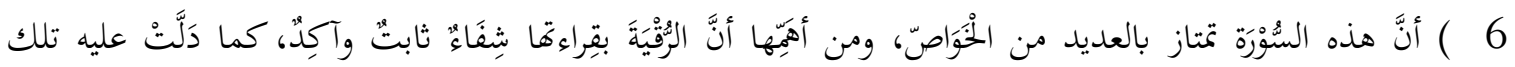

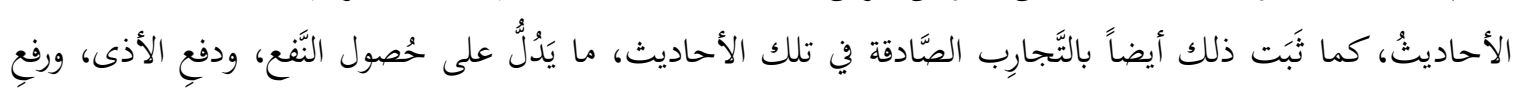

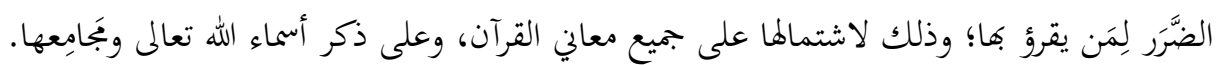

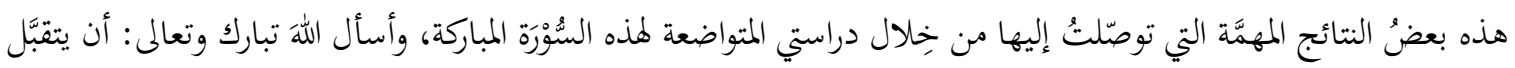

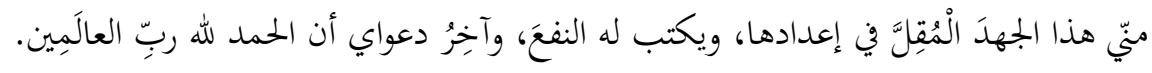
الهوامش:

1 انظر للتفصيل: عبد الرزاق حسين أمد، المكي والمدني في القرآن الكريع: دراسة تأصيلية نقدية للسور والآيات، (القاهرة: دار ابن عفان،

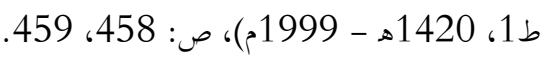

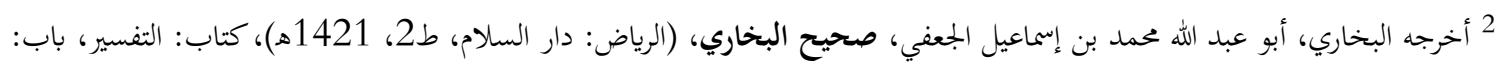

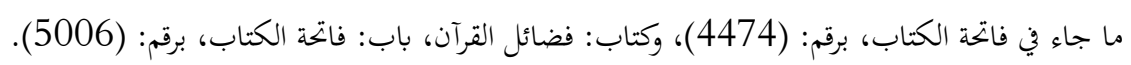

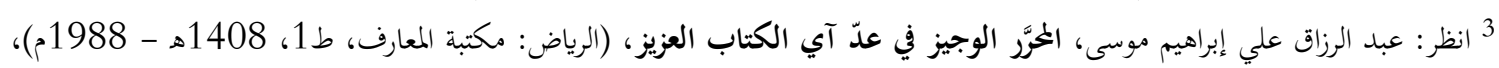
ص: 65.

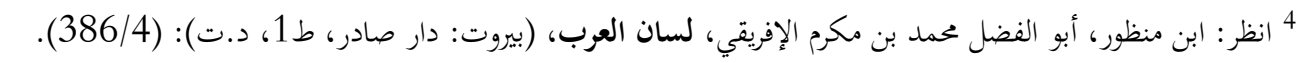

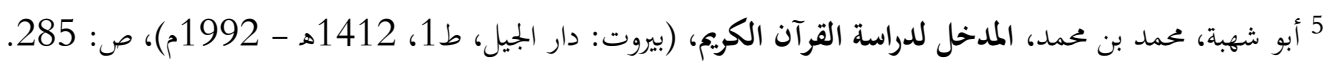

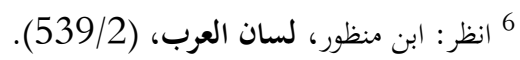
7 الكفوي، أبو البقاء أيوب بن موسى الحسيني، الكليات، (تحقيق: عدنان درويش وعممود المصري، بيروت: مؤسسة الرسالة، ط23، 1413هـ

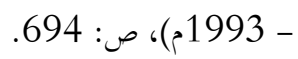

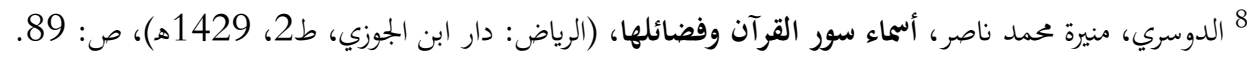

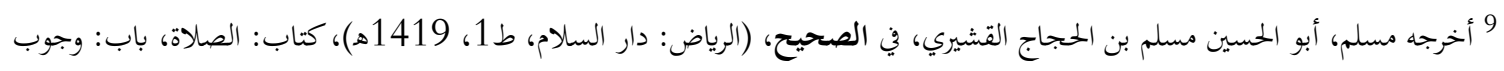

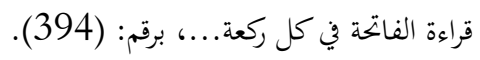

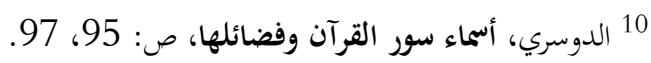

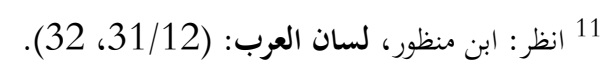
12 13 أخرجه أبو عيسى عمده بن عيسى بن سورة، في الجلمع، (الرياض: دار السلام، ط1، 1420ه)، كتاب: التفسير، باب: ومن سورة الحجر،

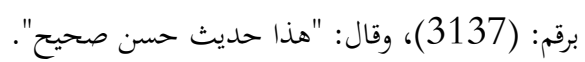
14 الدوسري، أسماء سور القرآن وفضائلها، ص: 103 : 103. 
15 انظر: ابن منظور، لسان العرب: (14/ 115، 119).

16 انظر: الطبري، أبو جعفر محمد بن جرير، جامع البيان في تأويل القرآن، (بيروت: دار الكتب العلمية، ط1، 1412هـ - 119 1992م):

17

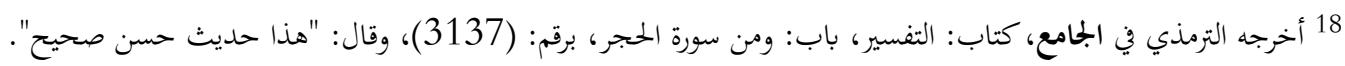

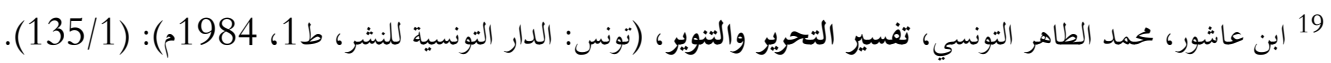

20 سبق تخريه.

21 أخرجه أمدا، أبو عبد الله أمد بن حنبل الشيباني، في المسند، (تحقيق: شعيب الأرناؤوط وآخرين، بيروت: مؤسسة الرسالة، ط2 287، 1429هن)،

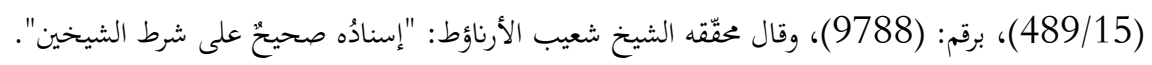

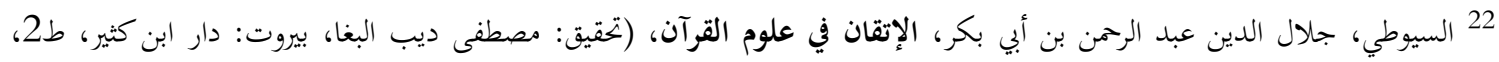

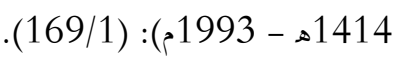

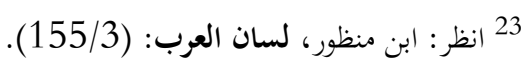

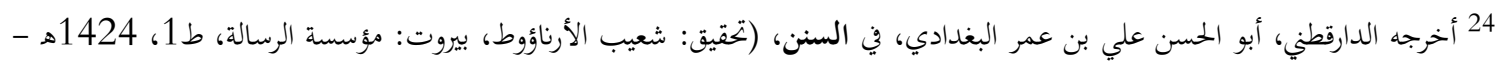

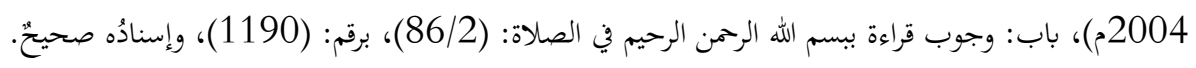

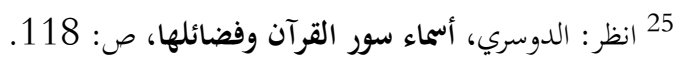

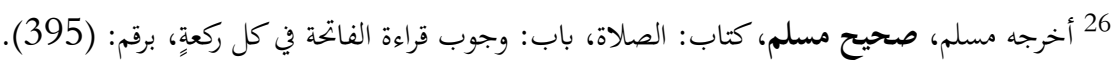

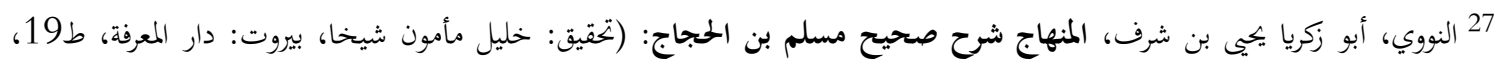

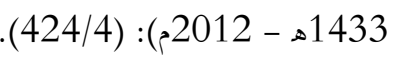

28 الزخشري، أبو القاسم جار الله عمود بن عمر، الكشاف عن حقوق التنزيل وعيون الأقاويل في وجوه التأويل، (بيروت: مكتبة المعارف، ط1، د.ت): (4/1).

29 الفيومي، أمد بن عمدا بن علي المقري، المصباح المنير في غريب الشحح الكبير، (تقيق: عبد العظيم الشناوي، القاهرة: دار المعارف، ط2،

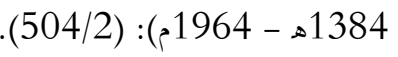

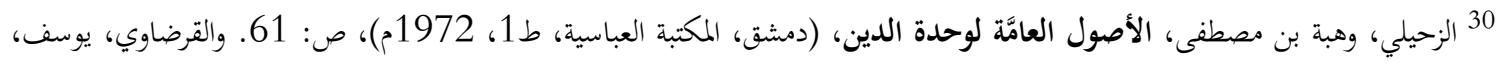

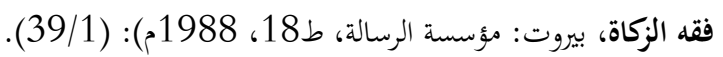

31 الشاطبي، أبو إسحاق إبراهيم بن موسى اللخمي، الموافقات في أصول الشريعة، (تحقيق: عبد الله دراز، بيروت: دار الكتب العلمية، ط1 المال،

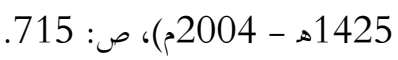

32 انظر: ابن عاشور، تفسير الننوير والتحرير: (133/1)، والصابوني، محمد علي، صفوة التفاسير، (بيروت: دار القرآن الكريم، ط4،

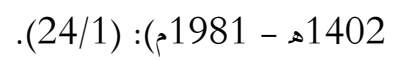
33 انظر: ابن منظور، لسان العرب: (1402) (24/7).

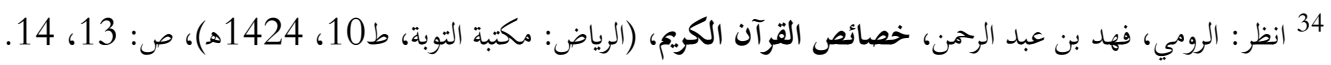

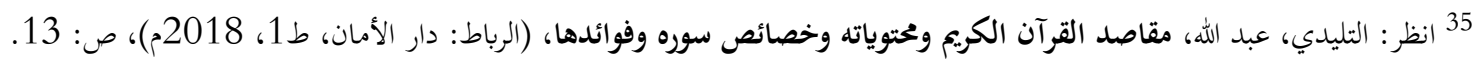


36 انظر: ابن منظور، لسان العرب: (524/11).

37 انظر: الهويل، تركي بن سعد بن فهيد، خواص القرآن الكريم: دراسة نظرية تطبيقية، (الرياض: دار ابن الجوزي، ط1، 1429ه)، ص:

38

39 انظر: ابن حجر، أبو الفضل أمد بن علي العسقاني، فتح الباري شح صحيح البخاري: (الرياض: دار السلام، ط1، 1421ه)،

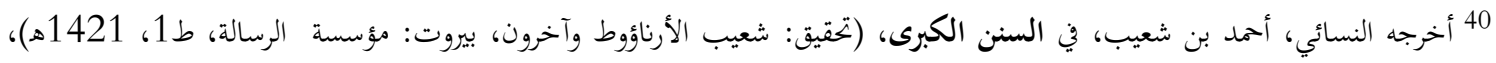

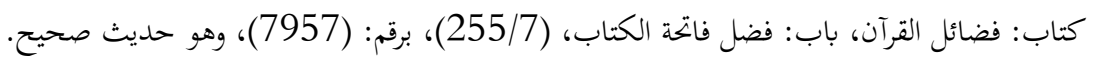
41 انظر: ابن حجر، فتح الباري: (198/8).

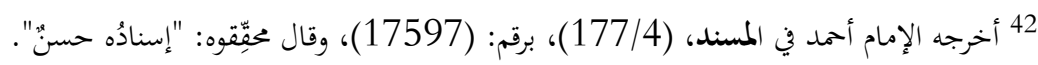

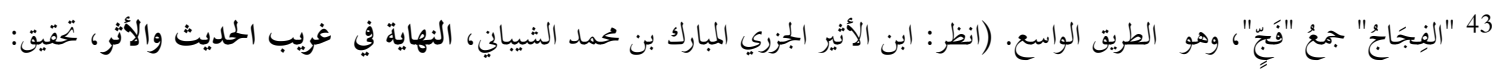

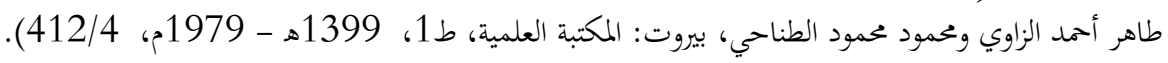

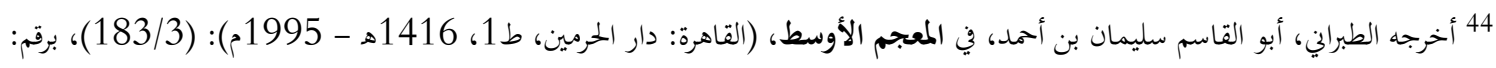

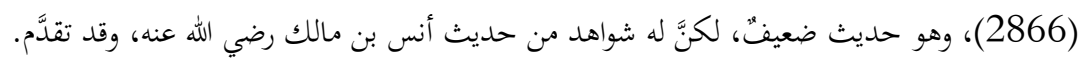

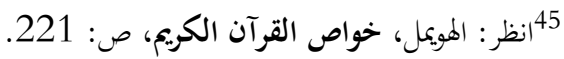

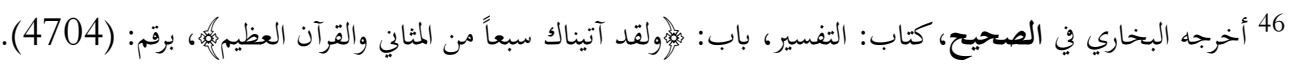
47 سبق تخريه. 48

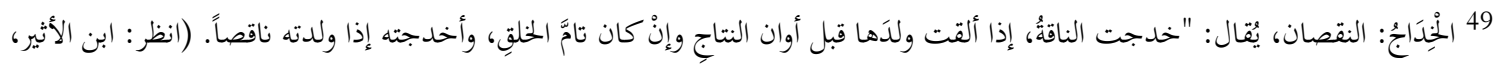

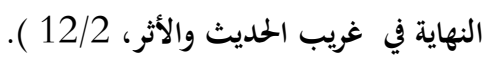

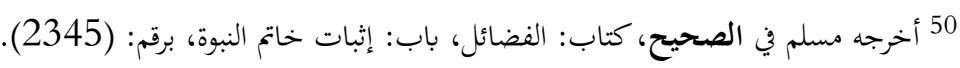

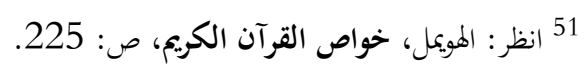

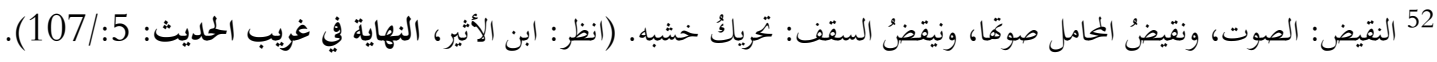

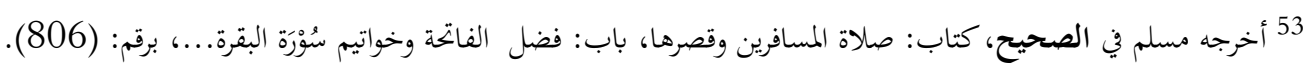

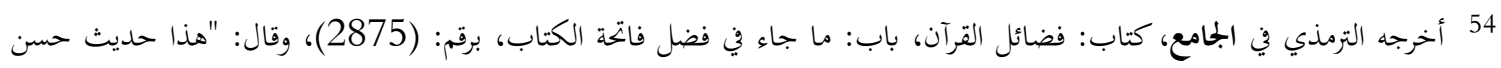
صحيح".

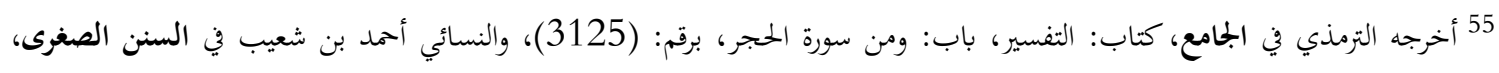

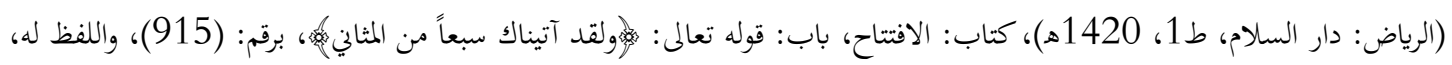
وقال الترمذي: "حديث حسن غريب". ( 56 سبق تخريه. أخرجه أبو داود في السنن، كتاب: الصلاة، باب: من ترك القراءة في صلاته بفاتحة الكتاب، برقم: (819)، وهو حديث صحيح. 
58 أخرجه ابن ماجه، أبو عبد الله محمد بن يزيد الربعي، في السنن، (الرياض: دار السلام، ط1، 1420ه)، كتاب: الصلاة، باب: القراءة خلف الإمام، برقم: (841)، وإسنادُه حسنُ.

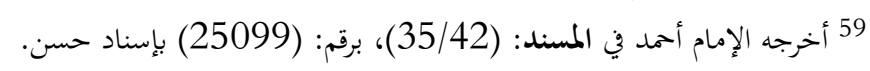

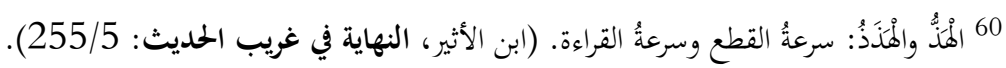

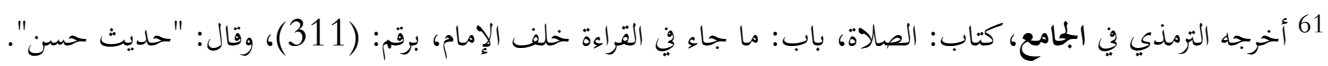

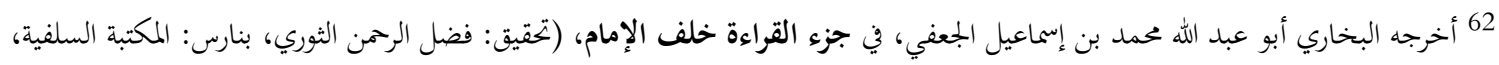

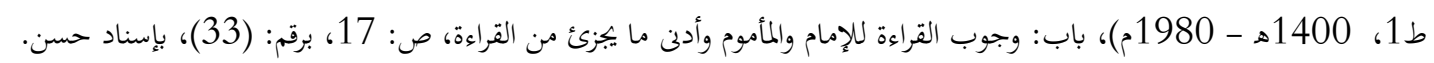

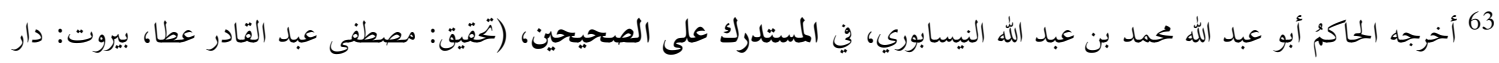

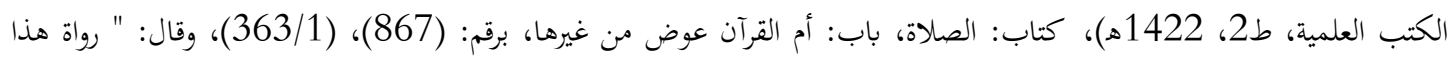

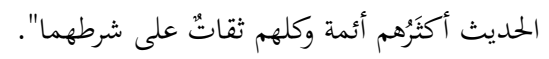

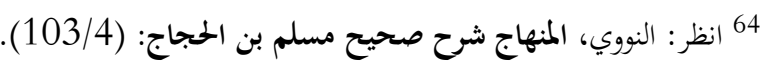

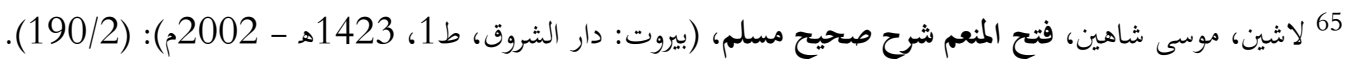

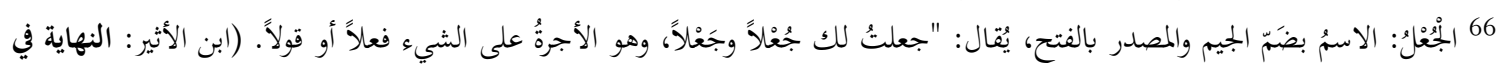

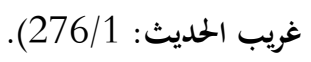

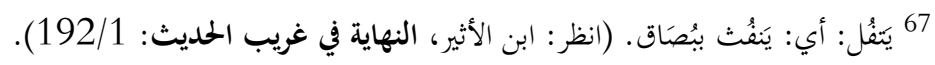

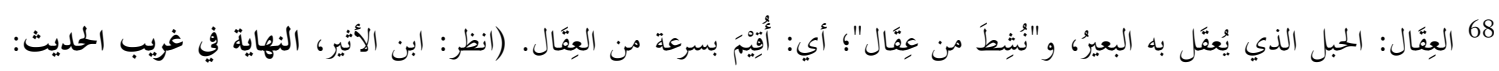
. 280/3

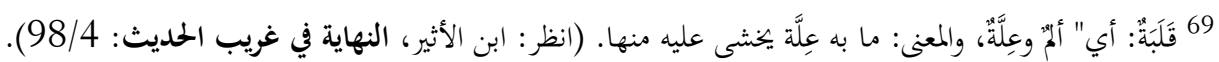

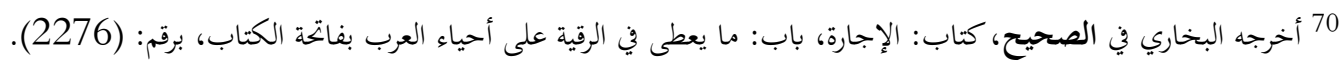

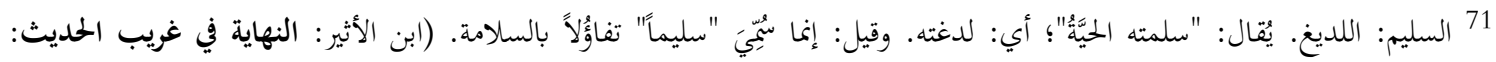
.). (396/2

72 أخرجه البخاري في الصحيح، كتاب: الطب، باب: الشروط في الرقية بفاتحة الكتاب، برقم: (5737).

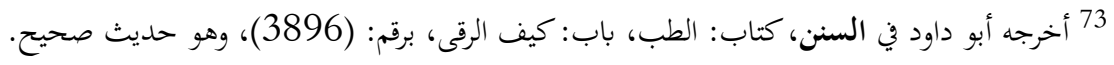

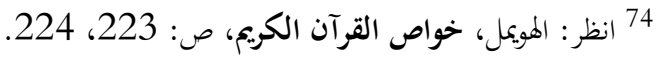

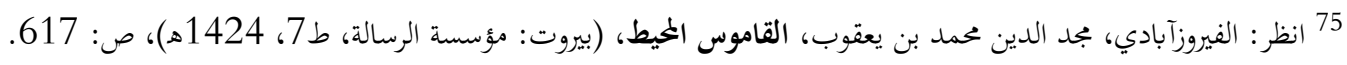

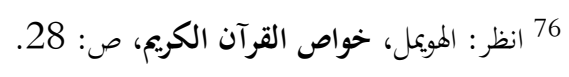

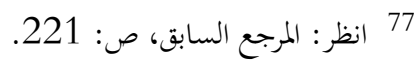
78 انظر: الزحيلي، وهبة بن مصطفى، الفقه الإسلامي وأدلنه، (بيروت: دار الفكر، ط1، 1404هـ - 1404 1984م): (653/1).

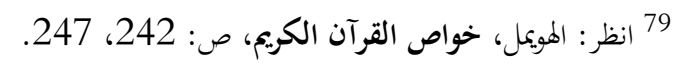

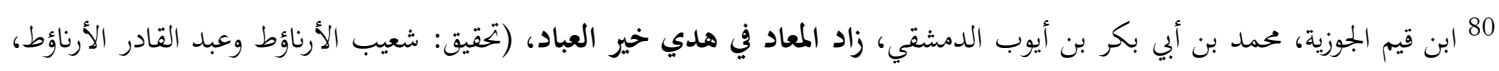

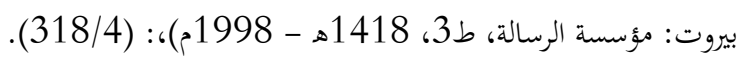




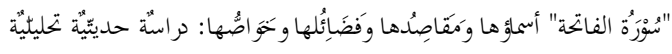

Al - Aijaz (July - Sep 2021)

81 ابن قيم الجوزية، محمد بن أبي بكر بن أيوب الدمشقي، مدارج السالكين بين منازل إياك نعبد وإياك نستعين، (تحقيق: محمد معتصم بالله

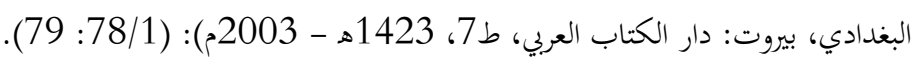

82 ابن القيم، زاد المعاد: (178/4). 